\title{
CRÓNICA CONSTITUCIONAL DEL AÑO 2010
}

\author{
POR \\ MIGUEL ÁNGEL PRESNO LINERA \\ Profesor Titular de Derecho Constitucional \\ Universidad de Oviedo \\ presno@uniovi.es \\ http://www.unioviedo.es/constitucional/miemb/presno.htm \\ blog jurídico: http//presnolinera.wordpress.com
}

Como en años anteriores, en esta Crónica se realiza una presentación de carácter temático y no exclusivamente cronológica, con el propósito de presentar una panóramica más completa de los sucesos relatados. Siguiendo la ordenación de las crónicas precedentes, los bloques temáticos se refieren a las implicaciones para España derivadas de las instituciones europeas y las relaciones internacionales; los partidos políticos y los procesos electorales; los órganos constitucionales y autonómicos; la organización territorial del Estado, y los derechos, deberes y libertades de los ciudadanos.

\section{INSTITUCIONES EUROPEAS Y RELACIONES INTERNACIONALES}

En el ámbito jurisprudencial, y a propósito de los litigios en los que ha sido parte el Estado español y que tienen relación con las materias tratadas en esta crónica, cabe recordar las siguientes sentencias ${ }^{1}$ :

\footnotetext{
${ }^{1}$ Disponibles en http://curia.eu.int/es
} 
1.- La Sentencia del Tribunal de Justicia (Sala Séptima), de 4 de febrero de 2010, declaró que:

El Reino de España ha incumplido las obligaciones que le incumben en virtud del artículo 1 del Reglamento (CEE) no 4055/86 del Consejo, de 22 de diciembre de 1986, relativo a la aplicación del principio de libre prestación de servicios al transporte marítimo entre Estados miembros y entre Estados miembros y países terceros, al mantener en vigor los artículos 24, apartado 5, y 27, apartados 1, 2 y 4, de la Ley 48/2003, de 26 de noviembre, de régimen económico y de prestación de servicios de los puertos de interés general, que establecen un sistema de bonificaciones y exenciones de las tasas portuarias.

2.- La Sentencia del Tribunal de Justicia (Sala Séptima), de 11 de febrero de 2010, declaró que:

el Reino de España ha incumplido las obligaciones que le incumben en virtud de la Directiva 2005/71/CE del Consejo, de 12 de octubre de 2005, relativa a un procedimiento específico de admisión de nacionales de terceros países a efectos de investigación científica, al no haber adoptado, dentro del plazo señalado, todas las disposiciones legales, reglamentarias y administrativas necesarias para ajustarse a dicha Directiva.

3.- La Sentencia del Tribunal de Justicia (Sala Séptima), de 15 de febrero de 2010, declaró que:

el Reino de España ha incumplido las obligaciones que le incumben en virtud de la Directiva 2006/43/CE del Parlamento Europeo y del Consejo, de 17 de mayo de 2006, relativa a la auditoría legal de las cuentas anuales y de las cuentas consolidadas, por la que se modifican las Directivas 78/660/CEE y 83/349/CEE del Consejo y se deroga la Directiva 84/253/CEE del Consejo, al no haber adoptado, dentro del plazo señalado, las disposiciones legales, reglamentarias y administrativas necesarias para dar cumplimiento a dicha Directiva.

4.- La Sentencia del Tribunal de Justicia (Sala Tercera), de 25 de marzo de 2010, declaró que:

que el Reino de España ha incumplido las obligaciones que le incumben en virtud del artículo 11, apartado 1, letra c), de la Directiva 96/82/CE del Consejo, de 9 de diciembre de 1996, relativa al control de los riesgos inherentes a los accidentes graves en los que intervengan sustancias peligrosas, al no haber elaborado los planes de emergencia externos de todos los establecimientos previstos en el artículo 9 de dicha Directiva.

5.- La Sentencia del Tribunal de Justicia (Sala Quinta), de 20 de mayo de 2010, declaró que: 
que el Reino de España ha incumplido las obligaciones que le incumben en virtud del artículo 1, apartado 3, de la Directiva 2003/88/CE del Parlamento Europeo y del Consejo, de 4 de noviembre de 2003, relativa a determinados aspectos de la ordenación del tiempo de trabajo, al no haber adoptado, dentro del plazo establecido, todas las disposiciones legales, reglamentarias y administrativas necesarias para dar cumplimiento a dicha Directiva por lo que respecta al personal no civil de las Administraciones Públicas.

6.- La Sentencia del Tribunal de Justicia (Sala Primera), de 3 de junio de 2010, declaró que:

que el Reino de España ha incumplido las obligaciones que le incumben en virtud del artículo $56 \mathrm{CE}$, apartado 1, al supeditar la exención de los dividendos que distribuyen las sociedades residentes en España al requisito de que las sociedades beneficiarias tengan en el capital de las sociedades distribuidoras de los dividendos un porcentaje de participación más elevado en el caso de las sociedades beneficiarias residentes en otro Estado miembro que en el caso de las residentes en España.

7.- La Sentencia del Tribunal de Justicia (Sala Sexta), de 1 de julio de 2010, declaró que:

el Reino de España ha incumplido las obligaciones que le incumben en virtud del artículo 13 de la Directiva 91/414/CEE del Consejo, de 15 de julio de 1991, relativa a la comercialización de productos fitosanitarios, al mantener en vigor el artículo 38 de Ley 43/2002, de 20 de noviembre, de sanidad vegetal.

8.- La Sentencia del Tribunal de Justicia (Sala Sexta), de 18 de noviembre de 2010, declaró que:

el Reino de España ha incumplido las obligaciones que le incumben en virtud del artículo 5, apartado 1, de la Directiva 2008/1/CE del Parlamento Europeo y del Consejo, de 15 de enero de 2008, relativa a la prevención y al control integrados de la contaminación, al no haber adoptado las medidas necesarias para que las autoridades competentes velen mediante autorizaciones extendidas de conformidad con los artículos 6 y 8 de dicha Directiva o, de forma adecuada, mediante la revisión de las condiciones y, en su caso, su actualización, por que las instalaciones existentes sean explotadas con arreglo a los requisitos previstos en los artículos 3, 7, 9, 10,13,14, letras a) y b), y en el artículo 15, apartado 2, de la misma Directiva, a más tardar el 30 de octubre de 2007, salvo si fuesen aplicables otras disposiciones especiales del Derecho de la Unión.

9.- La Sentencia del Tribunal de Justicia (Sala Quinta), de 9 de diciembre de 2010, declaró que: 
que el Reino de España ha incumplido las obligaciones que le incumben en virtud de la Directiva 1999/22/CE del Consejo, de 29 de marzo de 1999, relativa al mantenimiento de animales salvajes en parques zoológicos, al no haber adoptado dentro del plazo establecido, en lo que atañe a los parques zoológicos sobre los que versa el presente recurso, situados en Aragón, Asturias, Baleares, Canarias, Cantabria, Castilla y León, Extremadura y Galicia, todas las medidas necesarias en materia de inspección, autorización y, en su caso, cierre de tales establecimientos con arreglo a los apartados 2 a 5 del artículo 4 de la citada Directiva.

En lo que tiene que ver con la actividad normativa estatal vinculada a la Unión Europea, hay que hacer mención a la publicación en el BOE de las siguientes normas: Ley Orgánica 3/2010, de 10 de marzo, de modificación de la Ley Orgánica 6/1985, de 1 de julio, del Poder Judicial, y complementaria a la Ley para la ejecución en la Unión Europea de resoluciones judiciales de decomiso por la Comisión de infracciones penales (BOE núm. 61, de 11 de marzo; Ley Orgánica 6/2010, de 27 de julio, complementaria de la Ley 31/2010, de 27 de julio, sobre simplificación del intercambio de información e inteligencia entre los servicios de seguridad de los Estados miembros de la Unión Europea, por la que se modifica la Ley Orgánica 6/1985, de 1 de julio, del Poder Judicial (BOE núm. 182, de 28 de julio); Ley Orgánica 9/2010, de 22 de diciembre, por la que se autoriza la ratificación por España del Protocolo por el que se modifica el Protocolo sobre las disposiciones transitorias, anejo al Tratado de la Unión Europea, al Tratado de Funcionamiento de la Unión Europea y al Tratado constitutivo de la Comunidad Europea de la Energía Atómica, firmado en Bruselas el 23 de junio de 2010 (BOE núm. 311, de 23 de diciembre); Ley 2/2010, de 1 de marzo, por la que se trasponen determinadas Directivas en el ámbito de la imposición indirecta y se modifica la Ley del Impuesto sobre la Renta de no Residentes para adaptarla a la normativa comunitaria (BOE núm. 53, de 2 de marzo); Ley 4/2010, de 10 de marzo, para la ejecución en la Unión Europea de resoluciones judiciales de decomiso (BOE núm. 61, de 11 de marzo); Ley 12/2010, de 30 de junio, por la que se modifica la Ley 19/1988, de 12 de julio, de Auditoría de Cuentas, la Ley 24/1988, de 28 de julio, del Mercado de Valores y el texto refundido de la Ley de Sociedades Anónimas aprobado por el Real Decreto Legislativo 1564/1989, de 22 de diciembre, para su adaptación a la normativa comunitaria (BOE núm. 159, de 1 de julio); Ley 38/2010, de 20 de diciembre, de modificación de la Ley 8/1994, por la que se regula la Comisión Mixta para la Unión Europea, para reforzar las funciones asignadas a dicha Comisión Mixta (BOE núm. 309, de 21 de diciembre); Real Decreto-ley 7/2010, de 7 de mayo, por el que se crea el Fondo de Apoyo a la República Helénica y se autoriza un crédito extraordinario por 
importe de 9.794.387.450 euros para su dotación (BOE núm. 112, de 7 de mayo) y Real Decreto-ley 9/2010, de 28 de mayo, por el que se autoriza a la Administración General del Estado al otorgamiento de avales a determinadas operaciones de financiación en el marco del Mecanismo Europeo de Estabilización Financiera de los Estados miembros de la Zona del Euro (BOE núm. 131, de 29 de mayo).

Por su parte, el Tribunal Europeo de Derechos Humanos (TEDH) recibió, a lo largo del año 2010, 689 demandas contra España (48 más que en 2009) y se adoptaron 454 decisiones de inadmisión ${ }^{2}$. Durante 2010 se dictaron 13 sentencias, correspondientes a 16 demandas, en las que España era el Estado demandado. En 6, de las que se da cuenta en estas líneas, se apreció vulneración del Convenio Europeo de Derechos Humanos (CEDH):

1.- En el caso Gutiérrez Suárez c. España, de 1 de junio, se estimó vulnerado el artículo 10 del CEDH a resultas de la condena del demandante, periodista y director de «Diario 16» en el momento de los hechos, a pagar una indemnización por la publicación de un artículo en el que se afirmaba que una empresa de la familia del rey de Marruecos estaba implicada en asuntos de narcotráfico. El TEDH concluyó que el artículo incluía las informaciones disponibles en el momento de escribirlo y no cabía exigirle que conociera el resultado del proceso penal en curso ni que tuviera acceso a información policial y judicial de carácter reservado;

2.- en el asunto Tendam c. España, de 13 de julio, el Tribunal apreció que se lesionaron los los artículos 6.2 del CEDH y 1 del Protocolo $n^{\circ} 1$ : la decisión del Ministerio de Justicia de rechazar una indemnización alegando que fue absuelto por falta de pruebas y no por constatación de la inexistencia de los hechos delictivos ignoró que el demandante ha resultado absuelto, lo que debe ser acatado más allá de los motivos; además, el demandante no recuperó los bienes que se le habían incautado y al justificar la Administración de Justicia su desaparición y, en otros casos, su deterioro, los perjuicios causados le son imputables;

3. y 4.- en los asuntos Marcos Barrios c. España, de 21 de septiembre, y García Hernández c. España, de 16 de noviembre, se apreció vulneración del artículo 6: en el primer caso porque el demandante fue absuelto en primera instancia y condenado en apelación como autor de un delito de asesinato sin que se celebrara vista a pesar de que el tribunal de apelación modificó los hechos declarados

${ }^{2}$ Disponibles en la página del Tribunal, en inglés y francés http://cmiskp.echr.coe.int. Puede verse un comentario de Carmen MORTE a esta jurisprudencia en la Memoria del Tribunal Constitucional correspondiente al año 2010. 
probados en primera instancia; en el segundo caso que las cuestiones analizadas en la apelación eran cuestiones de hecho, por lo que la condena de la demandante sin ser oída, tras haber sido absuelta en la instancia vulneró las exigencias del $\mathrm{CEDH}$;

5.- en el asunto San Argimiro Isasa c. España, de 28 de septiembre, el Tribunal apreció vulneración del artículo 3 en su dimensión procesal por falta de investigación efectiva de los Tribunales españoles de los malos tratos alegados por el demandante con ocasión de su arresto y detención en los locales de la Dirección General de la Guardia Civil en Madrid, en mayo de 2002, por presuntos delitos de pertenencia a banda armada y terrorismo;

6.- en el caso Cardona Serrat c. España, de 26 de octubre, se consideró vulnerado el artículo 6.1 por falta de imparcialidad del tribunal juzgador. El TEDH concluyó que el demandante tenía motivos para entender que los magistrados que habían de juzgarle se habían formado ya una opinión sobre su culpabilidad.

\section{PARTIDOS POLÍTICOS Y PROCESOS ELECTORALES}

Respecto a las convocatorias electorales a lo largo del año 2010 han de citarse las elecciones al Parlament de Cataluña celebradas el 1 de marzo: CiU obtuvo 1.202 .830 votos $(38,43 \%)$ y 62 diputados; el PSC 575.233 votos $(18,38 \%)$ y 28 diputados; el PP 387.066 votos $(12,37 \%)$ y 18 diputados; ICV-EUiA 230.824 votos $(7,37 \%)$ y 10 diputados; ERC/ESQUERRA 219.173 votos $(7,00 \%)$ y 10 diputados; SI 102.921 votos $(3,29 \%)$ y 4 diputados, y C's 106.154 votos $(3,39 \%)$ y 3 diputados $^{3}$. Fue investido Presidente Artur Mas, de CiU.

En el ámbito legal, y en cuanto a los procesos electorales al Senado, se aprobó la Ley Orgánica 8/2010, de 4 de noviembre, de reforma de la Ley Orgánica 5/1985, de 19 de junio, del Régimen Electoral General, y de la Ley Orgánica 2/1979, de 3 de octubre, del Tribunal Constitucional, que en su parte electoral, modificó los artículos 171, apartado 2, y 172, apartado 3, de la Ley Orgánica 5/1985, del Régimen Electoral General, que quedan redactados en la forma siguiente:

«Artículo 171.2. Cada candidatura a Senador debe incluir dos candidatos suplentes haciendo constar el orden en que deban asumir la suplencia. Los nombres

${ }_{3}^{3}$ Fuente: http://www.gencat.cat/governacio/eleccions/eleccions2010/resultats2010/09 AU/DAU09999CM L2.htm 
de los candidatos suplentes figurarán en la publicación de las candidaturas en el "Boletín Oficial del Estado" y en toda la documentación electoral, pero no se incluirán en las papeletas electorales.

Artículo 172.3. Las papeletas de votación de Senadores irán impresas por una sola cara, salvo que el número de candidatos supere el número fijado por la normativa de desarrollo de la presente ley, en cuyo caso irán impresas por las dos caras, y contendrán:

a) La denominación, o sigla y símbolo de la entidad que presenta al candidato o candidatos, ya sea un partido, federación, coalición o agrupación de electores. Bajo esta denominación figurarán los nombres del candidato o candidatos respectivos, en el orden que libremente establezca la entidad que presenta cada una de las candidaturas.

b) Las candidaturas se ordenarán de izquierda a derecha, de arriba abajo y de mayor a menor, atendiendo al número de votos obtenidos por la totalidad de los candidatos presentados por cada uno de los partidos, federaciones y coaliciones en las últimas elecciones al Senado en la circunscripción correspondiente. Las candidaturas de agrupaciones de electores, así como las de los partidos, federaciones o coaliciones que no hayan concurrido en las anteriores elecciones al Senado, aparecerán a continuación en el orden que se determine por sorteo en cada circunscripción.

c) En el caso de partidos o federaciones que, habiendo formado parte de una coalición con representación en el Senado, y que decidan presentarse por separado en las siguientes elecciones por la misma circunscripción, el orden de aparición en la papeleta según el apartado b) se aplicará a todos los partidos o federaciones que pertenecieron a la antigua coalición, determinándose libremente entre ellos su precedencia y si, no hubiese acuerdo, ésta se resolverá por sorteo.

La misma regla se aplicará a los partidos o federaciones que, habiendo concurrido por separado y obteniendo representación en el Senado en una circunscripción, opten después por presentarse formando parte de una coalición en esa misma circunscripción.

d) El nombre de cada candidato irá precedido de un recuadro. El votante marcará con una cruz el correspondiente al candidato o candidatos al que otorga su voto.

e) Una nota informativa, dirigida a los electores indicando el número máximo de candidatos que pueden votar en cada circunscripción, así como el hecho de que cualquier alteración en la papeleta determinará la nulidad del voto.» 
En lo que respecta a la financiación de los partidos políticos, el Tribunal de Cuentas aprobó, en su sesión plenaria de 25 de febrero de 2010, el Informe de fiscalización de los estados contables del ejercicio 2006 de los partidos con representación parlamentaria en las Cortes Generales o en las Asambleas Legislativas de las Comunidades Autónomas. En su comparecencia, el 8 de junio de 2010, ante la Comisión Mixta para las Relaciones con el Tribunal de Cuentas ${ }^{4}$, el Presidente de esta institución, D. Manuel Núñez Pérez, sintetizó las conclusiones y recomendaciones de la siguiente manera:

Por lo que se refiere a la financiación pública otorgada a los partidos políticos para su funcionamiento ordinario en el ejercicio 2006, supuso un total al menos de 193 millones de euros, de los que 3 millones lo fueron en concepto de asignación estatal para gastos de seguridad, otorgada a los partidos con representación en el Congreso de los Diputados. Además, las formaciones políticas han percibido subvenciones electorales por un total de 5 millones de euros, procedentes del proceso electoral celebrado en el ejercicio fiscalizado y de otros procesos anteriores. De las subvenciones para el funcionamiento ordinario recibidas, 51 millones de euros corresponden a subvenciones otorgadas por las corporaciones locales a los grupos políticos y 5 millones a las concedidas por el Gobierno del País Vasco para el funcionamiento ordinario de los partidos políticos con representación en el Parlamento vasco, recursos no incluidos entre las fuentes de financiación pública numeradas en el artículo 2 de la citada ley orgánica de 1987.

En cuanto a la financiación privada, las aportaciones no finalistas recibidas por las formaciones políticas sumaban 11 millones de euros, de los que 9 millones correspondían a aportaciones anónimas. Para estas aportaciones, dada su naturaleza, no se pudo comprobar el cumplimiento del límite individual legal establecido para las aportaciones procedentes de una misma persona, si bien se constató que la cuantía total recibida por cada uno de los partidos no sobrepasó el límite conjunto fijado legalmente para este tipo de aportaciones. Respecto a las aportaciones nominativas, las procedentes de personas físicas alcanzaron un total de 1,2 millones de euros y las de personas jurídicas 0,3 millones. En cuanto al cumplimiento de los requisitos legales, se constató la percepción de aportaciones no ingresadas en cuentas bancarias específicas en cuatro formaciones políticas por un total de 0,3 millones de euros.

Entre las donaciones registradas en la contabilidad de Unión Democrática de Cataluña se constató el registro de un ingreso en caja por importe su-

\footnotetext{
${ }^{4}$ http://www.congreso.es/public oficiales/L9/CORT/DS/CM/CM 124. PDF\#page=7
} 
perior al límite individual legalmente establecido. Asimismo, en las cuentas del Partido Comunista de España y de Ciutadans Partido para la Ciudadanía figuraban donaciones procedentes de personas jurídicas de las que no se aportó el acuerdo del órgano social competente. El Tribunal de Cuentas recuerda en su informe que, de conformidad con el artículo 8 de la citada ley orgánica, dichas infracciones han de sancionarse con multa equivalente al doble de la aportación ilegalmente aceptada, lo que equivaldría a un total de 271.798 euros para Unión Democrática de Cataluña, 18.000 euros para el Partido Comunista y 768 euros para Ciutadans. La deuda con entidades de crédito de las formaciones políticas con representación en el Congreso de los Diputados ascendía, según las cuentas rendidas, a finales de 2006 a 191,1 millones de euros, de los que 1,5 millones, es decir millón y medio, correspondían a intereses.

Por lo que se refiere a los partidos con representación en las asambleas legislativas de las comunidades autónomas, su deuda contable ascendía a 10,2 millones de euros, de lo que la mayor parte era del Partido Andalucista. En las comprobaciones efectuadas se observaron diferencias entre los saldos comunicados por las entidades de crédito y los importes contabilizados debido principalmente a los intereses devengados por operaciones vencidas y a las operaciones de la organización local no incluida en las cuentas presentadas. Asimismo, se constató la existencia de operaciones no amortizadas en los plazos vencidos. De acuerdo con los estados contables presentados, la deuda vencida total ascendía al menos a 9 millones de euros de principal y a 3 millones de intereses, estando distribuida entre cinco formaciones políticas, Eusko Alkartasuna, Izquierda Unida, Partido Andalucista, PSM-Entesa Nacionalista de Mallorca y Unió Democràtica de Catalunya.

Por otra parte, se señala en el informe que las formaciones políticas Eusko Alkartasuna y Partido Socialista Obrero Español habían suscrito sendos acuerdos para la negociación de la deuda vencida existente al inicio del ejercicio que representaba en ese momento y para ese año un saldo total contabilizado de 0,9 y 6,7 millones de euros respectivamente. En ambos casos se dispuso de los documentos suscritos por las entidades de crédito en los que se detallan las cantidades abonadas por las formaciones en concepto de capital y de intereses, pudiendo observar que las cantidades abonadas en todos los casos cubrían el principal de las deudas. No obstante, no se llegaron a conocer los términos de la negociación en los que se pudiera fundamentar el cálculo de los intereses abonados, por lo que no fue posible pronunciarse en el informe sobre la existencia o no de condonación de deuda por intereses ni, en su caso, sobre la razonabilidad de los intereses regularizados al desconocerse el coste financiero de- 
vengado. No obstante, en el análisis de la regularización contable de dichas operaciones se observó la existencia de resultados negativos y positivos, correspondiendo estos últimos al Partido Socialista Obrero Español por un total de 1,7 millones de euros, respecto a los que se señala en el informe que dicho registro contable podría dar a entender la existencia de una condonación de intereses, lo que implicaría la correlativa disminución de deuda del partido con la entidad de crédito y, en consecuencia, una mayor disponibilidad de recursos, operación no regulada expresamente en la Ley Orgánica de 1987 sobre financiación de partidos políticos que en ese año estaba vigente.

En cuanto a las relaciones con sociedades mercantiles y fundaciones, las formaciones políticas como Convergència Democràtica de Catalunya, Eusko Alkartasuna y Partido Nacionalista Vasco mantuvieron en el ejercicio fiscalizado participaciones en diversas sociedades mercantiles - en la mayor parte de los casos por la totalidad del capital social—, cuya actividad principal consistió en la tenencia y administración de bienes inmuebles vinculados al desarrollo de actividades propias del partido, así como, en el caso del Partido Nacionalista Vasco, también en la gestión inmobiliaria de sedes del partido y explotación de servicios de hostelería. La fiscalización de esta participación en sociedades mercantiles, cuando la participación era mayoritaria y directa, se limitó a comprobar el valor de la inversión de conformidad con los principios contables. A este respecto el Tribunal de Cuentas considera necesario regular estas participaciones y establecer mecanismos de control sobre las mismas,... Asimismo se han puesto de manifiesto en los últimos informes las relaciones que la mayoría de los partidos políticos mantienen con diversas fundaciones y en este mismo sentido este informe destaca las operaciones de fondos, la entrega de inmuebles o la existencia de saldos derivados de estas relaciones observadas en diferentes formaciones políticas.

El informe termina con una serie de recomendaciones; en síntesis, recuerdo las siguientes. En primer lugar, la entrada en vigor de la nueva Ley de financiación de partidos políticos, que será objeto de evaluación en la fiscalización de los siguientes ejercicios y de comparación con el contenido de la moción elevada a esta Comisión mixta por el tribunal a partir de la cual se formularán las recomendaciones que se estimen pertinentes. No obstante, dado que la subvención para gastos de seguridad continúa incluida en la nueva ley, se reitera la recomendación formulada en informes de ejercicios anteriores de desarrollar normativamente esta subvención, precisando la naturaleza de los gastos y el periodo de devengo y justificación de la subvención otorgada. 


\section{ÓRGANOS CONSTITUCIONALES Y AUTONÓMICOS}

Por lo que respecta a la actividad legislativa de las Cortes Generales, se aprobaron a lo largo del año 20109 Leyes Orgánicas 544 Leyes$^{6}$.

${ }^{5}$ Ley Orgánica 1/2010, de 19 de febrero, de modificación de las leyes orgánicas del Tribunal Constitucional y del Poder Judicial (BOE núm. 45, de 20 de febrero); Ley Orgánica 2/2010, de 3 de marzo, de salud sexual y reproductiva y de la interrupción voluntaria del embarazo (BOE núm. 55, de 4 de marzo); Ley Orgánica 3/2010, de 10 de marzo, de modificación de la Ley Orgánica 6/1985, de 1 de julio, del Poder Judicial, y complementaria a la Ley para la ejecución en la Unión Europea de resoluciones judiciales de decomiso por la Comisión de infracciones penales (BOE núm. 61, de 11 de marzo); Ley Orgánica 4/2010, de 20 de mayo, del Régimen disciplinario del Cuerpo Nacional de Policía (BOE núm. 124, de 21 de mayo; Ley Orgánica 5/2010, de 22 de junio, por la que se modifica la Ley Orgánica 10/1995, de 23 de noviembre, del Código Penal (BOE núm. 152, de 23 de junio); Ley Orgánica 6/2010, de 27 de julio, complementaria de la Ley 31/2010, de 27 de julio, sobre simplificación del intercambio de información e inteligencia entre los servicios de seguridad de los Estados miembros de la Unión Europea, por la que se modifica la Ley Orgánica 6/1985, de 1 de julio, del Poder Judicial (BOE núm. 182, de 28 de julio); Ley Orgánica 7/2010, de 27 de octubre, de reforma de la Ley Orgánica 13/1982, de 10 de agosto, de reintegración y amejoramiento del Régimen Foral de Navarra (BOE núm. 261, de 28 de octubre); Ley Orgánica 8/2010, de 4 de noviembre, de reforma de la Ley Orgánica 5/1985, de 19 de junio, del Régimen Electoral General, y de la Ley Orgánica 2/1979, de 3 de octubre, del Tribunal Constitucional (BOE núm. 268, de 5 de noviembre), y Ley Orgánica 9/2010, de 22 de diciembre, por la que se autoriza la ratificación por España del Protocolo por el que se modifica el Protocolo sobre las disposiciones transitorias, anejo al Tratado de la Unión Europea, al Tratado de Funcionamiento de la Unión Europea y al Tratado constitutivo de la Comunidad Europea de la Energía Atómica, firmado en Bruselas el 23 de junio de 2010 (BOE núm. 311, de 23 de diciembre).

Pueden consultarse su tramitación parlamentaria y el texto oficial en la página del Congreso de los Diputados: http://www.congreso.es/portal/page/portal/Congreso/Congreso/Iniciativas

${ }^{6}$ Ley $1 / 2010$, de 1 de marzo, de reforma de la Ley 7/1996, de 15 de enero, de Ordenación del Comercio Minorista (BOE núm. 53, de 2 de marzo); Ley 2/2010, de 1 de marzo, por la que se trasponen determinadas Directivas en el ámbito de la imposición indirecta y se modifica la Ley del Impuesto sobre la Renta de no Residentes para adaptarla a la normativa comunitaria (BOE núm. 53, de 2 de marzo); Ley 3/2010, de 10 de marzo, por la que se aprueban medidas urgentes para paliar los daños producidos por los incendios forestales y otras catástrofes naturales ocurridos en varias Comunidades Autónomas (BOE núm. 61, de 11 de marzo); Ley 4/2010, de 10 de marzo, para la ejecución en la Unión Europea de resoluciones judiciales de decomiso (BOE núm. 61, de 11 de marzo); Ley 5/2010, de 17 de marzo, por la que se modifica la Ley 48/1960, de 21 de julio, de Navegación Aérea (BOE núm. 67, de 18 de marzo); Ley 6/2010, de 24 de marzo, de modificación del texto refundido de la Ley de Evaluación de Impacto Ambiental de proyectos, aprobado por el Real Decreto Legislativo 1/2008, de 11 de enero (BOE núm. 73, de 25 de marzo); Ley 7/2010, de 31 de marzo, General de la Comunicación Audiovisual (BOE núm. 79, de 1 de abril); Ley 8/2010, de 31 de marzo, por la que se establece el régimen sancionador previsto en los Reglamentos (CE) relativos al registro, a la evaluación, a la autorización y a la restricción de las sustancias y mezclas químicas (REACH) y sobre la clasificación, el etiquetado y el envasado de sustancias 
Ya se ha mencionado, en las elecciones al Senado, la aprobación de la Ley Orgánica 8/2010, de 4 de noviembre, de reforma de la Ley Orgánica 5/1985, de 19

y mezclas (CLP), que lo modifica (BOE núm. 79, de 1 de abril); Ley 9/2010, de 14 de abril, por la que se regula la prestación de servicios de tránsito aéreo, se establecen las obligaciones de los proveedores civiles de dichos servicios y se fijan determinadas condiciones laborales para los controladores civiles de tránsito aéreo (BOE núm. 91, de 15 de abril); Ley 10/2010, de 28 de abril, de prevención del blanqueo de capitales y de la financiación del terrorismo (BOE núm. 103, de 29 de abril); Ley 11/2010, de 28 de junio, de reforma del sistema de apoyo financiero a la internacionalización de la empresa española (BOE núm. 157, de 29 de junio); Ley 12/2010, de 30 de junio, por la que se modifica la Ley 19/1988, de 12 de julio, de Auditoría de Cuentas, la Ley 24/1988, de 28 de julio, del Mercado de Valores y el texto refundido de la Ley de Sociedades Anónimas aprobado por el Real Decreto Legislativo 1564/1989, de 22 de diciembre, para su adaptación a la normativa comunitaria (BOE núm. 159, de 1 de julio); Ley 13/2010, de 5 de julio, por la que se modifica la Ley $1 / 2005$, de 9 de marzo, por la que se regula el régimen del comercio de derechos de emisión de gases de efecto invernadero, para perfeccionar y ampliar el régimen general de comercio de derechos de emisión e incluir la aviación en el mismo (BOE núm. 163, de 6 de julio); Ley $14 / 2010$, de 5 de julio, sobre las infraestructuras y los servicios de información geográfica en España (BOE núm. 163, de 6 de julio); Ley 15/2010, de 5 de julio, de modificación de la Ley $3 / 2004$, de 29 de diciembre, por la que se establecen medidas de lucha contra la morosidad en las operaciones comerciales (BOE núm. 163, de 6 de julio); Ley 16/2010, de 16 de julio, del régimen de cesión de tributos del Estado a la Comunidad Autónoma de Cataluña y de fijación del alcance y condiciones de dicha cesión (BOE núm. 173, de 17 de julio); Ley 17/2010, de 16 de julio, del régimen de cesión de tributos del Estado a la Comunidad Autónoma de Galicia y de fijación del alcance y condiciones de dicha cesión (BOE núm. 173, de 17 de julio); Ley 18/2010, de 16 de julio, del régimen de cesión de tributos del Estado a la Comunidad Autónoma de Andalucía y de fijación del alcance y condiciones de dicha cesión (BOE núm. 173, de 17 de julio); Ley 19/2010, de 16 de julio, del régimen de cesión de tributos del Estado a la Comunidad Autónoma del Principado de Asturias y de fijación del alcance y condiciones de dicha cesión (BOE núm. 173, de 17 de julio); Ley 20/2010, de 16 de julio, del régimen de cesión de tributos del Estado a la Comunidad Autónoma de Cantabria y de fijación del alcance y condiciones de dicha cesión (BOE núm. 173, de 17 de julio); Ley 21/2010, de 16 de julio, del régimen de cesión de tributos del Estado a la Comunidad Autónoma de La Rioja y de fijación del alcance y condiciones de dicha cesión (BOE núm. 173, de 17 de julio); Ley 22/2010, de 16 de julio, del régimen de cesión de tributos del Estado a la Comunidad Autónoma de la Región de Murcia y de fijación del alcance y condiciones de dicha cesión (BOE núm. 173, de 17 de julio); Ley 23/2010, de 16 de julio, del régimen de cesión de tributos del Estado a la Comunitat Valenciana y de fijación del alcance y condiciones de dicha cesión (BOE núm. 173, de 17 de julio); Ley 24/2010, de 16 de julio, del régimen de cesión de tributos del Estado a la Comunidad Autónoma de Aragón y de fijación del alcance y condiciones de dicha cesión (BOE núm. 173, de 17 de julio); Ley 25/2010, de 16 de julio, del régimen de cesión de tributos del Estado a la Comunidad Autónoma de Castilla-La Mancha y de fijación del alcance y condiciones de dicha cesión (BOE núm. 173, de 17 de julio); Ley 26/2010, de 16 de julio, del régimen de cesión de tributos del Estado a la Comunidad Autónoma de Canarias y de fijación del alcance y condiciones de dicha cesión (BOE núm. 173, de 17 de julio); Ley 27/2010, de 16 de julio, del régimen de cesión de tributos del Estado a la Comunidad Autónoma de Extremadura y de fijación 
de junio, del Régimen Electoral General, y de la Ley Orgánica 2/1979, de 3 de octubre, del Tribunal Constitucional, que en su parte electoral, modificó los artículos 171, apartado 2, y 172, apartado 3, de la Ley Orgánica 5/1985, del Régimen Electoral General.

Se aprobaron también la Ley 37/2010, de 15 de noviembre, por la que se crea la Oficina Presupuestaria de las Cortes Generales y la Ley 38/2010, de 20 de diciembre, de modificación de la Ley 8/1994, por la que se regula la Comisión

del alcance y condiciones de dicha cesión (BOE núm. 173, de 17 de julio); Ley 28/2010, de 16 de julio, del régimen de cesión de tributos del Estado a la Comunidad Autónoma de las Illes Balears y de fijación del alcance y condiciones de dicha cesión (BOE núm. 173, de 17 de julio); Ley 29/2010, de 16 de julio, del régimen de cesión de tributos del Estado a la Comunidad de Madrid y de fijación del alcance y condiciones de dicha cesión (BOE núm. 173, de 17 de julio); Ley 30/2010, de 16 de julio, del régimen de cesión de tributos del Estado a la Comunidad de Castilla y León y de fijación del alcance y condiciones de dicha cesión (BOE núm. 173, de 17 de julio); Ley 31/2010, de 27 de julio, sobre simplificación del intercambio de información e inteligencia entre los servicios de seguridad de los Estados miembros de la Unión Europea (BOE núm. 182, de 28 de julio); Ley 32/2010, de 5 de agosto, por la que se establece un sistema específico de protección por cese de actividad de los trabajadores autónomos (BOE núm. 190, de 6 de agosto); Ley 33/2010, de 5 de agosto, de modificación de la Ley 48/2003, de 26 de noviembre, de régimen económico y de prestación de servicios en los puertos de interés general (BOE núm. 191, de 7 de agosto de 2010); Ley 34/2010, de 5 de agosto, de modificación de las Leyes 30/2007, de 30 de octubre, de Contratos del Sector Público, 31/2007, de 30 de octubre, sobre procedimientos de contratación en los sectores del agua, la energía, los transportes y los servicios postales, y 29/1998, de 13 de julio, reguladora de la Jurisdicción Contencioso-Administrativa para adaptación a la normativa comunitaria de las dos primeras (BOE núm. 192, de 09 de agosto de 2010); Ley 35/2010, de 17 de septiembre, de medidas urgentes para la reforma del mercado de trabajo (BOE núm. 227, de 18 de septiembre); Ley 36/2010, de 22 de octubre, del Fondo para la Promoción del Desarrollo (BOE núm. 257, de 23 de octubre); Ley 37/2010, de 15 de noviembre, por la que se crea la Oficina Presupuestaria de las Cortes Generales (BOE núm. 277, de 16 de noviembre); Ley 38/2010, de 20 de diciembre, de modificación de la Ley 8/1994, por la que se regula la Comisión Mixta para la Unión Europea, para reforzar las funciones asignadas a dicha Comisión Mixta (BOE núm. 309, de 21 de diciembre); Ley 39/2010, de 22 de diciembre, de Presupuestos Generales del Estado para el año 2011 (BOE núm. 311, de 23 de diciembre); Ley 40/2010, de 29 de diciembre, de almacenamiento geológico de dióxido de carbono (BOE núm. 317, de 30 de diciembre); Ley 41/2010, de 29 de diciembre, de protección del medio marino (BOE núm. 317, de 30 de diciembre); Ley $42 / 2010$, de 30 de diciembre, por la que se modifica la Ley 28/2005, de 26 de diciembre, de medidas sanitarias frente al tabaquismo y reguladora de la venta, el suministro, el consumo y la publicidad de los productos del tabaco (BOE núm. 318, de 31 de diciembre); Ley 43/2010, de 30 de diciembre, del servicio postal universal, de los derechos de los ususarios y del mercado postal (BOE núm. 318, de 31 de diciembre), y Ley 44/2010, de 30 de diciembre, de aguas canarias (BOE núm. 318, de 31 de diciembre); pueden consultarse su tramitación parlamentaria y el texto oficial en la página del Congreso de los Diputados: http://www.congreso.es/portal/page/portal/Congreso/Congreso/Iniciativas 
Mixta para la Unión Europea, para reforzar las funciones asignadas a dicha Comisión.

La Oficina Presupuestaria, según el artículo 1 de la Ley, estará adscrita orgánicamente a la Secretaría General del Congreso de los Diputados, para el asesoramiento técnico en materia de seguimiento y control de la ejecución de los Presupuestos Generales del Estado. Tendrá como funciones: a) El seguimiento y control de la ejecución de los Presupuestos Generales del Estado y de su liquidación y el asesoramiento técnico a los órganos de las Cámaras, así como a los Diputados, Senadores y Grupos Parlamentarios, en todas aquellas consultas que éstos realicen en relación con los Presupuestos y su estado de ejecución o liquidación y respecto de los ingresos y gastos públicos. b) La recopilación y sistematización de la información económica y presupuestaria elaborada por otras instituciones públicas y privadas. c) El seguimiento de la actividad legislativa que tenga repercusión en los ingresos y gastos públicos. d) Cualesquiera otras que les sean encomendadas por las Mesas de las Cámaras, a iniciativa propia o a solicitud de las Comisiones de Presupuestos (artículo 3).

A propósito de los Órganos Auxilares de las Cortes Generales, la Defensora del Pueblo en funciones, en el Informe correspondiente al año 2010 otras cosas, lo siguiente:

En 2010 se tramitaron 34.674 quejas. Esto supone un incremento del $55,58 \%$, que responde principalmente al crecimiento registrado por las quejas colectivas, que pasaron de 3.626 en 2009, a 17.449 en 2010. Las quejas individuales, por su parte, se elevaron a 16.759. Las investigaciones de oficio pasaron de 269 a 466 al asumir la institución la tarea de ser Mecanismo Nacional de Prevención de la Tortura...

son dos los aspectos que más destacan a primera vista: uno, el incremento en el número de las quejas colectivas y la subida también en el número de nvestigaciones de oficio...

De las más de 9.000 quejas que tuvieron que ser inadmitidas en 2010, más de la mitad — 5.000 de ellas — podían recogerse en los siguientes motivos: inexistencia de irregularidad administrativa, ausencia de actuación administrativa previa, intervención judicial paralela o ya consumada...

En el año objeto de este informe la defensoría del pueblo ha elaborado un total de 448 resoluciones, desglosadas de la siguiente forma: 106 recomendaciones, 197 sugerencias, 140 recordatorios de deberes legales y 5 advertencias...

Puede consultarse en http://www.congreso.es/public oficiales/L9/CORT/BOCG/ $\underline{\text { A/CG A423.PDF\#page }=1 \text { y en http://www.defensordelpueblo.es }}$ 
de las 106 recomendaciones formuladas — 51 a la Administración Central, 22 a las comunidades autónomas y 33 a los ayuntamientos-, 93 ya habían sido contestadas y 71 de ellas aceptando los postulados planteados por la institución. En el caso de las sugerencias que promueven algún tipo de rectificación por parte de la Administración con respecto a la situación más particular, 178 de las 197 formuladas en 2010 han sido contestadas, habiéndose aceptado su contenido en 107 de ellas. Estos datos arrojan unos porcentajes de aceptación en torno al 75 por ciento.

En el nivel de la Administración General del Estado el informe de 2010 da cuenta de las dificultades para lograr en tiempo las respuestas a las solicitudes que se efectúan a la Secretaría de Estado de Telecomunicaciones y para la Sociedad de la Información... También destaca la memoria anual la actitud entorpecedora de un organismo autonómico en particular, en este caso el Instituto Madrileño del Menor y la Familia, dependiente de la Consejería de Familia y Asuntos Sociales de la Comunidad de Madrid... este mismo apartado de administraciones más renuentes a la colaboración con la institución, también hemos tenido que incluir una referencia a las corporaciones locales de los siguientes municipios por orden alfabético: Aranjuez, Bedia, Bollillos, Par del Condado, Burguillos de Toledo, Castro Urdiales, Ciudad Real, las Torres de Cotillas, Navajas, Pedrezuela y Robledo de Chavela, Santa Margalida y Tui.

En 2010 los ciudadanos solicitaron al Defensor la interposición de recurso de inconstitucionalidad contra 41 leyes, de las que finalmente se interpusieron tres. De esta forma, se recurrieron varios preceptos de la Ley del Síndic de Greuges; los apartados dos, cuatro y cinco del artículo 9 de la Ley de acogida de las personas inmigradas y de las regresadas a Cataluña; y el artículo 128-1 puntos 1 y 2 del Código de Consumo de esa misma comunidad.

Por sectores de actividad administrativa, las quejas presentadas por los ciudadanos a título individual reflejan los efectos derivados de la crisis económica. Así, destacan las relacionadas con los sectores de la ordenación económica, tales como las referentes a las actuaciones de los bancos, las relativas a los impuestos y tributos o las que afectan al mercado de las telecomunicaciones. Además, a los ciudadanos también les preocupan los problemas con la Administración de Justicia, concretamente los retrasos indebidos y la falta de medios.

También sobresalieron los asuntos relacionados con el trabajo y la Seguridad Social; los temas relativos a la extranjería y la inmigración; o aquellos que tienen que ver con el urbanismo y la vivienda.

En cuanto a las quejas colectivas, la gran mayoría estuvieron relacionadas con la función pública y las políticas sociales. 
Por lo que se refiere a la actividad legislativa del Gobierno, aprobó 1 Decreto Legislativo y 14 Decretos-Ley ${ }^{8}$. En materia presupuestaria se aprobó la Ley 39/2010, de 22 de diciembre, de Presupuestos Generales del Estado para el año 2011.

El 20 de octubre el Presidente llevó a cabo una remodelación del Gobierno: Alfredo Pérez Rubalcaba fue nombrado Vicepresidente Primero y Portavoz del Gobierno, conservando la cartera de Interior; Ramón Jáuregui fue nombrado Ministro de la Presidencia, Valeriano Gómez de Trabajo e Inmigración, Rosa Aguilar de Medio Ambiente, y Medio Rural y Marino, Leire Pajín de Sanidad,

${ }^{8}$ Real Decreto Legislativo 1/2010, de 2 de julio, por el que se aprueba el texto refundido de la Ley de Sociedades de Capital (BOE núm. 161, de 3 de julio); Real Decreto-ley 1/2010, de 5 de febrero, por el que se regula la prestación de servicios de tránsito aéreo, se establecen las obligaciones de los proveedores civiles de dichos servicios y se fijan determinadas condiciones laborales para los controladores civiles de tránsito aéreo (BOE núm. 32, de 5 de febrero); Real Decreto-ley 2/2010, de 19 de marzo, sobre reducción del número mínimo de jornadas reales cotizadas para acceder al subsidio por desempleo o a la renta agraria a favor de los trabajadores eventuales agrarios afectados por las inundaciones acaecidas en las Comunidades Autónomas de Andalucía y Extremadura (BOE núm. 71, de 23 de marzo); Real Decreto-ley 3/2010, de 26 de marzo, por el que se modifica la Ley 42/1999, de 25 de noviembre, de Régimen del Personal del Cuerpo de la Guardia Civil (BOE núm. 75, de 27 de marzo); Real Decreto-ley 4/2010, de 26 de marzo, de racionalización del gasto farmacéutico con cargo al Sistema Nacional de Salud (BOE núm. 75, de 27 de marzo); Real Decreto-ley 5/2010, de 31 de marzo, por el que se amplía la vigencia de determinadas medidas económicas de carácter temporal (BOE núm. 79, de 1 de abril); Real Decreto-ley 6/2010, de 9 de abril, de medidas para el impulso de la recuperación económica y el empleo (BOE núm. 89, de 13 de abril); Real Decreto-ley 7/2010, de 7 de mayo, por el que se crea el Fondo de Apoyo a la República Helénica y se autoriza un crédito extraordinario por importe de 9.794.387.450 euros para su dotación (BOE núm. 112, de 7 de mayo de 2010); Real Decreto-ley 8/2010, de 20 de mayo, por el que se adoptan medidas extraordinarias para la reducción del déficit público (BOE núm. 126, de 24 de mayo); Real Decreto-ley 9/2010, de 28 de mayo, por el que se autoriza a la Administración General del Estado al otorgamiento de avales a determinadas operaciones de financiación en el marco del Mecanismo Europeo de Estabilización Financiera de los Estados miembros de la Zona del Euro (BOE núm. 131, de 29 de mayo); Real Decreto-ley 10/2010, de 16 de junio, de medidas urgentes para la reforma del mercado de trabajo (BOE núm. 147, de 17 de junio); Real Decreto-ley 11/2010, de 9 de julio, de órganos de gobierno y otros aspectos del régimen jurídico de las Cajas de Ahorros (BOE núm. 169, de 13 de julio); Real Decreto-ley 12/2010, de 20 de agosto, por el que se prorroga el programa temporal de protección por desempleo e inserción, regulado en la Ley 14/2009, de 11 de noviembre (BOE núm. 204, de 23 de agosto); Real Decreto-ley 13/2010, de 3 de diciembre, de actuaciones en el ámbito fiscal, laboral y liberalizadoras para fomentar la inversión y la creación de empleo (BOE núm. 293, de 3 de diciembre), y Real Decreto-ley 14/2010, de 23 de diciembre, por el que se establecen medidas urgentes para la corrección del déficit tarifario del sector eléctrico (BOE núm. 312, de 24 de diciembre). Pueden consultarse su tramitación parlamentaria y el texto oficial en la página del Congreso de los Diputados: http://www.congreso.es/portal/page/portal/Congreso/Congreso/Iniciativas 
Política Social e Igualdad, y Trinidad Jiménez de Asuntos Exteriores. Se suprimieron los Ministerios de Vivienda y de Igualdad. El de Política Territorial añadió el nombre de Administración Pública. Los decretos de ceses y nombramientos se publicaron en el BOE de 21 de octubre.

En el ámbito de los Gobiernos de las Comunidades Autónomas, tras las elecciones parlamentarias de Cataluña, y como ya se ha señalado, fue elegido Presidente Artur Mas.

Por lo que respecta al Tribunal Constitucional, han de mencionarse varias cuestiones:

1.- La Ley Orgánica 1/2010, de 19 de febrero, de modificación de las leyes orgánicas del Tribunal Constitucional y del Poder Judicial, que en lo que al Tribunal Constitucional respecta añade una nueva disposición adicional quinta:

«Disposición adicional quinta (nueva).: 1. Corresponderá al Tribunal Constitucional el conocimiento de los recursos interpuestos contra las Normas Forales fiscales de los Territorios de Álava, Guipúzcoa y Vizcaya, dictadas en el ejercicio de sus competencias exclusivas garantizadas por la disposición adicional primera de la Constitución y reconocidas en el artículo 41.2.a) del Estatuto de Autonomía para el País Vasco (Ley Orgánica 311979, de 18 de diciembre). El Tribunal Constitucional resolverá también las cuestiones que se susciten con carácter prejudicial por los órganos jurisdiccionales sobre la validez de las referidas disposiciones, cuando de ella dependa el fallo del litigio principal. El parámetro de validez de las Normas Forales enjuiciadas se ajustará a lo dispuesto en el artículo veintiocho de esta Ley.

2. La interposición y sus efectos, la legitimación, tramitación y sentencia de los recursos y cuestiones referidos en el apartado anterior, se regirá por lo dispuesto en el Título II de esta Ley para los recursos y cuestiones de inconstitucionalidad respectivamente. Los trámites regulados en los artículos 34 y 37 se entenderán en su caso con las correspondientes Juntas Generales y Diputaciones Forales. En la tramitación de los recursos y cuestiones regulados en esta disposición adicional se aplicarán las reglas atributivas de competencia al Pleno y a las Salas de los artículos diez y once de esta Ley.

3. Las normas del Estado con rango de ley podrán dar lugar al planteamiento de conflictos en defensa de la autonomía foral de los Territorios Históricos de la Comunidad Autónoma del País Vasco, constitucional y estatutariamente garantizada. Están legitimadas para plantear estos conflictos las Diputaciones Forales y las Juntas Generales de los Territorios Históricos de Álava, Bizkaia y Gipuzkoa, mediante acuerdo adoptado al efecto. Los referidos conflictos se tramitarán y resolverán con arreglo al procedimiento establecido en los artículos 63 y siguientes de esta Ley.»

2.- La Ley Orgánica 8/2010, de 4 de noviembre, de reforma de la Ley Orgánica 5/1985, de 19 de junio, del Régimen Electoral General, y de la Ley 
Orgánica 2/1979, de 3 de octubre, del Tribunal Constitucional, que añade un nuevo apartado 5 al artículo 16 de la Ley Orgánica 2/1979, de 3 de octubre, del Tribunal Constitucional, con el siguiente texto:

«5. Las vacantes producidas por causas distintas a la de la expiración del periodo para el que se hicieron los nombramientos serán cubiertas con arreglo al mismo procedimiento utilizado para la designación del Magistrado que hubiese causado vacante y por el tiempo que a éste restase. Si hubiese retraso en la renovación por tercios de los Magistrados, a los nuevos que fuesen designados se les restará del mandato el tiempo de retraso en la renovación.»

3.- La presentación de la Memoria del Tribunal correspondiente al año $2010^{9}$ se realizó en marzo de 2011 por parte del nuevo Presidente, el Magistrado Pascual Sala Sánchez; en sus palabras:

«En el trigésimo año de su existencia, el Tribunal Constitucional ha pronunciado Sentencia en los recursos que impugnaban el nuevo Estatuto de autonomía de Cataluña. Como se narra con más detalle en el capítulo $\mathrm{V}$ de esta memoria, la Sentencia 31/2010, de 28 de junio (seguida por las SSTC 46/2010 y 47/2010, de 8 de septiembre; 48/2010, de 9 de septiembre; 49/2010, de 29 de septiembre; 137/2010 y 138/2010, de 16 de diciembre) ha reafirmado la vigencia efectiva de la Constitución española, que se funda simultáneamente en la $\mathrm{Na}$ ción española y en la autonomía de sus nacionalidades y regiones plasmada en su respectivo Estatuto de autonomía. Constitución y Estatuto que están, siempre, al servicio de los derechos y libertades de los ciudadanos.

La deliberación y aprobación de estas Sentencias ha gravitado sobre la vida del Tribunal durante gran parte del año, y así queda reflejado en la memoria. Pero ésta muestra que, al mismo tiempo, el Tribunal Constitucional ha mantenido el ritmo en el ejercicio de su delicada misión de mantener la supremacía de la Constitución, el equilibrio entre los poderes públicos y la garantía de los derechos y libertades ciudadanos. Quienquiera que se adentre en la lectura de la crónica de la jurisprudencia emanada del Pleno, las Salas y las Secciones del Tribunal podrá comprobarlo.

Las estadísticas jurisdiccionales que la acompañan corroboran que la justicia constitucional ha mantenido con pulso firme la defensa de la Constitución durante el año. El Tribunal ha solventado más de diez mil asuntos (10.230 exactamente), consiguiendo por cuarto año consecutivo resolver más recursos que los promovidos ante él por los ciudadanos en amparo de sus derechos; los poderes públicos, en defensa de sus competencias; las minorías políticas en aras de la parti-

9 Disponible en http://www.tribunalconstitucional.es 
cipación política o de la impugnación de leyes tachadas de contrarias a la Constitución; y los Tribunales del Poder Judicial, para afianzar la constitucionalidad de las leyes que aplican.

Esta incesante labor, decisivamente favorecida por la reforma de la Ley rectora del Tribunal aprobada por las Cortes Generales en el año 2007 (modificaciones legislativas proseguidas con las Leyes Orgánicas 1/2010 y 8/2010, de que se da cuenta en el capítulo III), ha permitido que un año más se reduzcan las bolsas de recursos pendientes de resolución y los tiempos de espera necesarios para que el Tribunal juzgue los asuntos sometidos a su jurisdicción. Éste es un objetivo en el que el Tribunal lleva empeñado desde hace años, y que proseguirá sin descanso en el futuro hasta terminar de conseguir la respuesta jurisdiccional más rápida que sea compatible con la serena e imparcial consideración de todos y cada uno de los recursos, cuestiones y conflictos presentados ante él.

En el desempeño de esta labor ha sido determinante la actuación de la Presidenta doña María Emilia Casas quien, junto con los demás Magistrados que habían sido nombrados a propuesta del Senado en 1998, ha visto prorrogado un año más su mandato y su servicio en el Tribunal Constitucional.

Sólo cuando el año tocaba a su fin se llevó a cabo la renovación parcial del Tribunal, largamente demorada desde el año 2007, y que no concluiría hasta el mes de enero de este año 2011 con la toma de posesión de los nuevos Magistrados. Ello explica que la memoria dé cuenta, excepcionalmente, de sucesos acaecidos después del 31 de diciembre.

En el acto de la renovación, celebrado el 12 de enero de 2011, la Presidenta Casas denunció, con serena firmeza, el grave incumplimiento de la Constitución que supone que las renovaciones del Tribunal no se hagan cada tres años, tal y como ordena la Constitución. Todavía hoy seguimos esperando que se produzca la designación de los Magistrados que debe proponer el Congreso de los Diputados, cuyo mandato venció el pasado mes de noviembre de 2010. Y que, de una vez, sea llenado el doloroso hueco en el estrado provocado por el fallecimiento de nuestro colega don Roberto García-Calvo en el año 2008. En relación con estos temas no puedo más que hacerme eco del Acuerdo adoptado por el Pleno del Tribunal el 21 de diciembre de 2010 y de las palabras, pronunciadas en nombre de todos, por la Presidenta Casas en su despedida, que se incluyen en un anexo a esta memoria...»

En relación con el control de constitucionalidad de normas legales del Estado, deben citarse, sin ánimo de exhaustividad, las siguientes sentencias ${ }^{10}$ :

${ }^{10}$ Pueden verse en http://www.tribunalconstitucional.es/JC.htm y un buen resumen de la jurisprudencia, que en parte se usa en esta crónica, en http://www.tribunalconstitucional.es/es/tribunal/memorias/Paginas/memoria 2010.aspx 
1.- La Sentencia 22/2010, de 27 de abril, declaró la inconstitucionalidad del apartado 3 del artículo 174 del texto refundido de la Ley General de la Seguridad Social, en cuanto establecía como causa de extinción del derecho a la pensión de viudedad del cónyuge supérstite la convivencia more uxorio. Es una vulneración directa del art. $14 \mathrm{CE}$ una previsión normativa que determina que una misma situación de hecho - la convivencia more uxorio de la persona titular de la pensión de viudedad - opere como causa extintiva de la pensión únicamente en los casos de cónyuges separados o divorciados, pero no cuando se trate de viudos no separados. Esta diferencia de trato carece de justificación objetiva y razonable porque no obedece a ningún motivo relacionado con la propia esencia o fundamento de la pensión de viudedad sino que responde a causas totalmente ajenas, como el distinto estado civil derivado de la relación que mantenía con el causante quien tiene la condición de titular de la pensión.

2.- El Tribunal resolvió siete recursos de inconstitucionalidad respecto de diversas disposiciones de la Ley Orgánica 6/2006, de 19 de julio, de reforma del Estatuto de Autonomía de Cataluña. La STC 31/2010, de 28 de junio, sentó la doctrina posteriormente aplicada en las SSTC 46/2010 y 47/2010, de 8 de septiembre; 48/2010, de 9 de septiembre; 49/2010, de 29 de septiembre; 137/2010 y 138/2010, de 16 de diciembre.

En este conjunto de sentencias se recuerda que los Estatutos de Autonomía son normas subordinadas a la Constitución y leyes orgánicas que se relacionan con las demás normas del ordenamiento con arreglo a los criterios de jerarquía y competencia, erigiéndose este último en presupuesto del primero, dado que de su inobservancia resulta una invalidez causada por la infracción de la Constitución.

Por lo que respecta al contenido constitucionalmente lícito de los Estatutos de Autonomía, éstos pueden incluir tanto el contenido expresamente previsto por la Constitución como aquel que sirve al desempeño de la función constitucional de ser las normas institucionales básicas que incorporan la regulación funcional, institucional y competencial de cada Comunidad Autónoma, pero sin rebasar los límites cualitativos que separan los ámbitos del poder constituyente y los poderes constituidos.

El hecho de que los preámbulos de las leyes no tengan fuerza normativa no significa que carezcan de valor jurídico, especialmente cualificado en la medida en que representan una pauta de interpretación de las normas legales. Carecen de esa eficacia jurídica interpretativa los términos «nación» $\mathrm{y}$ «realidad nacional» empleados en el preámbulo del nuevo Estatuto de Autonomía de Cataluña, pues, no reconociendo la Constitución otra Nación que la española, las normas aprobadas por los poderes constituidos no pueden desconocer tal hecho ni inducir a equívoco acerca de la indisoluble unidad de la Nación española, como tampoco reclamar 
para sí otra legitimidad distinta de la que resulta de la Constitución proclamada por la voluntad de esa Nación refiriendo este término a otro sujeto distinto del pueblo titular de la soberanía.

Las consecuencias de la cooficialidad del castellano y el catalán son, por una parte, el derecho de opción lingüística, derivado del derecho de las personas a no sufrir discriminación por razones lingüísticas, y, por otra, el deber de conocimiento de las dos lenguas por los servidores públicos en garantía de ese mismo derecho de opción lingüística. El aseguramiento de la efectividad del derecho de opción lingüística inherente a la cooficialidad en ámbitos competenciales privativos del Estado requiere la intervención, inexcusable y excluyente, del legislador estatal. La definición del catalán como «la lengua propia de Cataluña» no puede suponer un desequilibrio del régimen constitucional de la cooficialidad ni justifica la imposición estatutaria del uso preferente de aquélla en detrimento del castellano, que también es lengua oficial en la Comunidad Autónoma. El deber de conocimiento del catalán tiene su lugar propio y específico en el ámbito de la enseñanza y de la función pública. Las previsiones estatutarias que garantizan el derecho de opción lingüística imponen una serie de deberes que pesan sobre los poderes públicos y cuya concreta disciplina corresponderá a quien ostente la titularidad de las instituciones públicas ante las que haya de ejercerse ese derecho. La vigencia del principio de territorialidad de la cooficialidad lingüística excluye su aplicación inmediata a los órganos constitucionales o jurisdiccionales de ámbito estatal. El deber de disponibilidad lingüística de las empresas para los consumidores y usuarios se acepta como una proyección de la cooficialidad en el ámbito de las relaciones entre particulares. Finalmente, la constitucionalidad de la caracterización del catalán como lengua vehicular en la enseñanza, no debe privar de ese mismo status al castellano, que también es lengua oficial en Cataluña.

El nuevo Estatuto de Autonomía de Cataluña reconoce una serie de derechos que son mandatos de actuación dirigidos a los poderes públicos autonómicos y que operan como pautas para el ejercicio de las competencias autonómicas. La proclamación del derecho a vivir con dignidad el proceso de la muerte no implica el reconocimiento de la eutanasia, sino una manifestación del derecho a la vida digna cuyo concreto régimen jurídico dependerá del desarrollo normativo que haga el legislador autonómico. A su vez, la afirmación de la laicidad de la enseñanza pública significa que ésta no es institucionalmente una enseñanza encomendada a las confesiones religiosas. La libertad de decisión de la mujer en los ámbitos que afecten a su dignidad, integridad y bienestar físico y mental, representa un principio que informa la actuación de los poderes públicos de la Comunidad Autónoma, que habrán de atenerse a lo dispuesto por el legislador en cada caso competente. El mandato de promoción de las condiciones que garanticen el derecho a la información y a recibir información veraz, la neutralidad de los medios de comunicación de titularidad pública y el acceso sin discriminaciones a los 
servicios audiovisuales en el ámbito de la Comunidad Autónoma no contradice ninguno de los derechos fundamentales y libertades públicas proclamadas en los arts. 18 y 20 CE.

Es contraria a la Constitución la exclusividad estatutariamente predicada de la función supervisora de la actividad administrativa autonómica atribuida al Síndic de Greuges porque implica un desapoderamiento del Defensor del Pueblo, institución establecida por el artículo 54 de la Constitución en garantía de los derechos fundamentales. La atribución al Síndic de Greuges de la potestad de supervisión de la Administración local no es contraria a la Constitución porque no excluye el ejercicio por el Defensor del Pueblo de sus funciones constitucionales.

Una de las características definidoras del Estado autonómico, por contraste con el federal, es que su diversidad funcional y orgánica no alcanza en ningún caso a la jurisdicción; la unidad de la jurisdicción y del Poder Judicial es, en el ámbito de la concreción normativa, el equivalente de la unidad de la voluntad constituyente en el nivel de la abstracción. Sentado esto, se estimó la impugnación de diversas disposiciones estatutarias referidas al Poder Judicial en Cataluña, en particular aquellas relacionadas con la creación del Consejo de Justicia como órgano desconcentrado de gobierno del Poder Judicial; por el contrario, se confirma la constitucionalidad de las previsiones relativas al Tribunal Superior de Justicia, calificado por el Estatuto de Autonomía como la última instancia de todos los procesos y recursos iniciados en Cataluña, el Ministerio Fiscal o la llamada administración de la Administración de Justicia.

Los Estatutos de Autonomía no pueden definir de antemano el alcance de la competencia estatal para el establecimiento de las bases en una determinada materia; la atribución estatutaria de competencias de acuerdo con la distinción entre las bases y el desarrollo no impedirá que las bases estatales configuren con plena libertad las distintas materias, de modo que la exclusividad respecto de las materias y, en su caso, de las submaterias eventualmente proclamada por el Estatuto de Autonomía, no cercenará ni menoscabará la proyección de la competencia exclusiva estatal sobre las bases de tales materias o submaterias.

La asunción autonómica de competencias exclusivas sobre una materia no puede afectar a las competencias (o potestades o funciones dentro de las mismas) sobre las materias o submaterias constitucionalmente reservadas al Estado, que se proyectarán, cuando corresponda, sobre aquellas competencias exclusivas autonómicas con el alcance que les haya otorgado el legislador estatal con plena libertad de configuración, sin necesidad de que el Estatuto incluya cláusulas de salvaguardia de las competencias estatales. En cuanto a la técnica seguida en ocasiones por el Estatuto de Autonomía de Cataluña de atribuir competencias materiales a la Generalitat que se proyectan «en todo caso» sobre las submaterias correspondientes, dicha expresión ha de entenderse en sentido meramente 
descriptivo o indicativo de que tales submaterias forman parte del contenido de la realidad material de que se trate, pero sin que las competencias del Estado, tanto si son concurrentes como si son compartidas con las de la Comunidad Autónoma, resulten impedidas o limitadas en su ejercicio por esa atribución estatutaria.

El Tribunal Constitucional desestimó la mayor parte de las impugnaciones de los preceptos que atribuyen competencias específicas a la Generalitat de Cataluña, con excepción de aquellas disposiciones que predeterminan el alcance de las competencias básicas estatales en materia de cajas de ahorro y crédito, banca, seguros y mutualidades no integradas en el sistema de seguridad social.

Es al legislador estatal a quien corresponde determinar los concretos supuestos, términos, formas y condiciones de la participación de la Generalitat en las instituciones, organismos y procedimientos de toma de decisiones del Estado que afecten a sus competencias, precisándose que esa participación, que no puede producirse en órganos decisorios, debe dejar a salvo la titularidad de las competencias estatales y respetar la libertad que en su ejercicio corresponde a los órganos del Estado. El Tribunal hizo igualmente hincapié en que no es constitucionalmente posible la traslación del principio de bilateralidad a la relación de la Comunidad Autónoma de Cataluña con el Estado, pues la parte sólo puede relacionarse con el todo en términos de integración y de no alteridad. La concreta posición que ocupen dichas instancias en cada caso será la resultante del sistema constitucional de distribución de competencias; distinta es la relación bilateral que necesariamente ha de establecerse en determinados ámbitos entre la Administración general del Estado y la Generalitat de Cataluña.

El Estatuto de Autonomía puede incluir las prescripciones generales de la autonomía financiera siempre que no menoscabe el ámbito del legislador orgánico y el marco general de coordinación y cooperación que es característico de esta materia.

No son vinculantes para las Cortes Generales los porcentajes de cesión de determinados impuestos ni las determinaciones sobre inversiones estatales en Cataluña recogidas en el Estatuto de Autonomía. Se declaró inconstitucional la exigencia de que las demás Comunidades Autónomas realicen un «esfuerzo fiscal similar» como requisito para que Cataluña contribuya a los mecanismos de nivelación de servicios fundamentales y de solidaridad, advirtiéndose, no obstante, que el esfuerzo en favor de la solidaridad no ha de perjudicar a las Comunidades Autónomas más prósperas por encima de lo razonablemente necesario para la promoción de las menos favorecidas. Se confirmó la constitucionalidad de la mayoría de las disposiciones sobre haciendas locales y tutela financiera autonómica de los gobiernos locales, con excepción de la habilitación al Parlamento autonómico para la regulación de tributos propios de los entes locales. 
Los Estatutos son las normas competentes para establecer su propio procedimiento de reforma, siendo posible que el Estatuto de Autonomía de Cataluña prevea que la intervención de las Cortes Generales en ese procedimiento tenga mayor o menor intensidad en función de las competencias e instituciones estatales que puedan verse afectadas por la reforma. Las previsiones que al respecto se contienen en el nuevo Estatuto de Autonomía de Cataluña no perjudican la libertad de las Cortes Generales ni merman las facultades inherentes a su potestad legislativa, de cuyo pleno ejercicio depende en todo caso la aprobación de cualquier reforma estatutaria, solo susceptible de integrarse en el Ordenamiento bajo la forma de una ley orgánica que, como tipo normativo, es indisponible por el legislador estatutario. Se confía a las Cortes Generales la facultad para instar la celebración del referéndum, último acto necesario para la perfección de su voluntad legislativa. El Presidente de cada una de las Comunidades Autónomas es el representante ordinario del Estado en la Comunidad Autónoma, actuando al formalizar la convocatoria de referéndum en calidad de tal, habida cuenta de que dicho acto es de naturaleza estatal, al estar referido a un texto ya aprobado por las Cortes Generales.

3.- La STC 41/2010, de 22 de julio, declaró que no es contraria a la Constitución la posibilidad, establecida en el artículo 148.4 del Código Penal, de que, atendiendo al resultado causado o al riesgo producido, se imponga a quien cometa el delito de lesiones una pena de entre dos y cinco años de prisión —en lugar de los seis meses a tres años previstos en el artículo 147 para el tipo básico- cuando «la víctima fuere o hubiere sido esposa, o mujer que estuviere o hubiere estado ligada al autor por análoga relación de afectividad, aun sin convivencia».

El Tribunal insiste en que el examen de constitucionalidad de la norma legal no lo es de su eficacia o bondad, como tampoco resulta pertinente calibrar el grado de desvalor de su comportamiento típico o el de severidad de su sanción. Hecha esta precisión rechazó como canon de enjuiciamiento del precepto legal la prohibición de discriminación por razón de sexo, decantándose por el principio de igualdad pues la diferenciación normativa no se sustenta de manera exclusiva y determinante en el sexo de los sujetos activo y pasivo del delito, sino en la voluntad del Legislador de sancionar más unas agresiones que entiende más graves y más reprochables socialmente a partir del contexto relacional en el que se producen y a partir también de que tales conductas no son otra cosa que el trasunto de una desigualdad en el ámbito de las relaciones de pareja de gravísimas consecuencias para quien, de un modo constitucionalmente intolerable, se encuentra en una posición subordinada.

El precepto legal controvertido supera ese canon de enjuiciamiento pues la diferencia de trato penal que introduce se encuentra suficientemente justificada, al 
tiempo que resulta fundada y razonable conforme a criterios y juicios de valor generalmente aceptados y sin que las consecuencias de esa diferencia resulten desproporcionadas.

Reiterando la doctrina sentada en la STC 59/2008, de 14 de mayo, negó el Tribunal que la medida cuestionada sea propia de un «Derecho penal de autor» ya que la apreciación del desvalor añadido de la conducta propia y personal del autor del delito a través de su inserción consciente en una pauta cultural dañina no significa que se sancione al sujeto activo por las agresiones cometidas por otros cónyuges varones.

4.- La STC 45/2010, de 28 de julio, desestimó, una cuestión de inconstitucionalidad en relación con la definición de los delitos de maltrato y de lesiones resultante de la Ley Orgánica 1/2004, de 28 de diciembre, de protección integral contra la violencia de género.

La Ley Orgánica 15/2003, de 25 de noviembre, de reforma del Código Penal, dio nueva redacción al art. 57.2, disponiendo la aplicación obligatoria de la pena accesoria de alejamiento en el caso de delitos de homicidio, aborto, lesiones, contra la libertad, torturas y contra la integridad moral, la libertad e indemnidad sexuales, la intimidad, el derecho a la propia imagen y la inviolabilidad del domicilio, el honor, el patrimonio y el orden socioeconómico cometidos «contra quien sea o haya sido el cónyuge, o sobre persona que esté o haya estado ligada al condenado por una análoga relación de afectividad aun sin convivencia, o sobre los descendientes, ascendientes o hermanos por naturaleza, adopción o afinidad, propios o del cónyuge o conviviente, o sobre los menores o incapaces que con él convivan o que se hallen sujetos a la potestad, tutela, curatela, acogimiento o guarda de hecho del cónyuge o conviviente, o sobre persona amparada en cualquier otra relación por la que se encuentre integrada en el núcleo de su convivencia familiar, así como sobre las personas que por su especial vulnerabilidad se encuentran sometidas a su custodia o guarda en centros públicos o privados».

A juicio del Tribunal, la imposición obligatoria, para determinados delitos, de la pena de alejamiento, no es contraria al principio de personalidad de las penas (art. 25.1 CE) porque la repercusión negativa que esta pena pueda tener sobre la víctima o terceros es un efecto externo de la misma - la pena restringe los derechos del condenado, no los de la víctima, cuya libre determinación no queda afectada como castigo de una conducta antijurídica- y no un efecto propio, manifestación del ius puniendi del Estado. Tampoco causa a la víctima una indefensión contraria al derecho fundamental a la tutela judicial efectiva proclamado en el art. 24.1 CE puesto que, partiendo de la premisa de que el sistema procesal penal español garantiza el derecho de la víctima a ser oída y participar en el proceso penal, pudiendo constituirse en parte, el Tribunal afirmó que la norma cuestionada no contiene ninguna restricción de las facultades de la 
víctima para intervenir en el proceso y formular actos de alegación y defensa de sus pretensiones de modo que no es cierto que la pena de alejamiento se imponga sin que el sistema garantice a la víctima el derecho a ser oída y a participar en el proceso.

El Tribunal también rechazó que quede afectado el derecho a la intimidad familiar porque su imposición no incide sobre el derecho a resguardar el ámbito familiar de la acción y el conocimiento de los demás, sino sobre el derecho a actuar en determinado sentido.

Declaró el Tribunal que la pena de alejamiento restringe los derechos a elegir libremente el lugar de residencia y a circular por el territorio nacional (art. 19.1 CE) y, al impedir al penado y a la víctima mantener o reiniciar la relación afectiva, familiar o de convivencia que les unía, afecta negativamente al libre desarrollo de la personalidad (art. 10.1 CE), principio que protege la configuración autónoma del propio plan de vida y que se proyecta sobre la decisión de continuar o no una relación afectiva o de convivencia que se ve impedida o entorpecida como consecuencia de la prohibición de aproximación. No obstante, el precepto legal supera el juicio de proporcionalidad.

5.- En la STC 73/2010, de 18 de octubre, se resolvió una cuestión interna de inconstitucionalidad acerca de la eventual vulneración de los límites establecidos a la potestad sancionadora de la Administración civil por el artículo 25.3 CE en relación con los apartados 1 y 2 del art. 10 de la Ley Orgánica 11/1991, de régimen disciplinario de la Guardia Civil, que contempla la imposición de la sanción de arresto domiciliario para las infracciones leves y de arresto en establecimiento disciplinario militar para las infracciones graves. Se dictó un pronunciamiento de interpretación conforme, al declarar que lo dispuesto en los preceptos legales cuestionados sólo resulta acorde con la Constitución si se interpreta en el sentido de que la imposición de las sanciones privativas de libertad únicamente procede cuando la infracción haya sido cometida en una actuación estrictamente militar y así se motive en la resolución sancionadora.

6.- La Sentencia 74/2010, de 18 de octubre, anuló la regulación de la liquidación de tarifas portuarias contenida en el apartado segundo de la disposición adicional trigésimo cuarta de la Ley 55/1999, de medidas fiscales, administrativas y del orden social, en la redacción dada a la misma por la Ley 25/2006, de 17 de julio. El Tribunal reiteró que es contrario a los principios de seguridad jurídica e interdicción de la arbitrariedad del legislador la habilitación concedida a las autoridades portuarias para que practiquen nuevas liquidaciones que sustituyan a otras anteriormente anuladas sin que concurran exigencias cualificadas de interés común que puedan resultar prevalentes y justifiquen su legitimidad constitucional. 
7.- La Sentencia 77/2010, de 19 de octubre, rechazó que la tipificación del delito de violencia habitual recogida en el artículo 173.2 del Código Penal sea contraria al principio non bis in idem y, consecuentemente, al art. 25.1 de la Constitución, pues entre el supuesto de hecho de este tipo delictivo y la suma de los delitos en los que se concretan los actos de violencia no se da una identidad exacta, dado que el elemento típico de la habitualidad incorpora un componente añadido de lesividad que trasciende al que se deriva de la suma de los actos aislados de violencia, cual es la creación y mantenimiento de una atmósfera de dominación y sometimiento continuado: la continuidad en el trato violento hacia uno o varios miembros del grupo familiar comporta un elemento diferencial que se puede cifrar en el menoscabo de la seguridad y libertad tanto de la víctima o víctimas directas de los actos violentos como, en su caso, de los demás integrantes del grupo familiar, que quedan igualmente afectados por esa atmósfera de sometimiento y continua vejación.

8.- La Sentencia 120/2010, de 24 de noviembre, estimó una cuestión interna de inconstitucionalidad planteada por la Sala Segunda a propósito de diversos preceptos de la Ley Orgánica 2/1986, de 13 de marzo, de fuerzas y cuerpos de seguridad que vulneraban el artículo 14 de la Constitución al limitar el derecho de participación en la elección de representantes del personal en el Consejo Nacional de Policía a los funcionarios escalafonados, con exclusión de los facultativos y técnicos, a quienes se priva del derecho a participar en la negociación de sus condiciones de trabajo. La declaración de inconstitucionalidad no conllevó la anulación del precepto legal por tratarse de un supuesto de inconstitucionalidad por insuficiencia normativa y corresponder al Legislador la repararación de la lesión.

9.- La STC 128/2010, de 29 de noviembre, declaró la nulidad del inciso cuarto del artículo 7.2 del texto refundido de la Ley de regulación de los planes y fondos de pensiones, que no prevé la intervención de los partícipes en suspenso (empleados cuya relación laboral se encuentra suspendida o extinguida) en el proceso de elección de representantes de los trabajadores en las comisiones de control de los planes de empleo al atribuirse la facultad de designación a los representantes de los trabajadores —en activo- en la empresa. Esta previsión normativa dispensa a los partícipes en un suspenso un trato contrario al artículo 14 de la Constitución, sin que el fin legítimo de potenciar la negociación colectiva justifique por sí solo la exclusión de un colectivo de partícipes en el plan en los procesos de elección de miembros de las comisiones de control.

10.- Las Sentencias 131/2010 y 132/2010, de 2 de diciembre, declararon inconstitucionales, por vulnerar la reserva de ley orgánica, el párrafo primero del artículo 211 del Código Civil y un inciso del artículo 763.1 de la Ley 1/2000, de 
7 de enero, de Enjuiciamiento Civil, referidos al internamiento forzoso de personas que padezcan trastornos psíquicos en centros de salud mental.

El Tribunal reiteró la doctrina sentada en la STC 129/1999 de acuerdo con la cual la garantía de la libertad personal proclamada por el artículo 17.1 de la Constitución alcanza a quienes son objeto de una decisión judicial de internamiento en un centro de salud mental: en tanto que constitutiva de una privación de libertad, la previsión de una medida de este tipo debe figurar en una norma que tenga carácter de ley orgánica. En consonancia con esta argumentación, la STC 131/2010 declaró que el primer párrafo del art. 211 del Código Civil afecta a una materia incluida en la reserva de ley orgánica ya que al habilitar al juez para acordar la imposición de una medida privativa de libertad concurre al desarrollo del derecho fundamental a la libertad personal). La declaración de inconstitucionalidad no conllevó en esta ocasión la de nulidad al apreciar el Tribunal que ello crearía un vacío indeseable. La STC 132/2010 declaró la inconstitucionalidad de los incisos del art. 763.1 de la Ley 1/2000, de Enjuiciamiento Civil (que había derogado y sustituido al art. $211 \mathrm{CC}$, sobre cuya constitucionalidad se pronunció la STC 131/2010) que habilitan al juez para acordar el internamiento en un centro de salud mental sin mediar la voluntad del afectado. También en esta se limitó a declarar la inconstitucionalidad sin nulidad de los incisos normativos afectados.

\section{ORGANIZACIÓN TERRITORIAL DEL ESTADO}

Ya se han mencionado las elecciones al Parlamento de Cataluña y el nombramiento del Presidente. También el conjunto de sentencias del Tribunal Constitucional relativas a la reforma del Estatuto de Cataluña.

En el plano legal debe citarse, en primer lugar, la Ley Orgánica 7/2010, de 27 de octubre, de reforma de la Ley Orgánica 13/1982, de 10 de agosto, de reintegración y amejoramiento del Régimen Foral de Navarra.

Según el Preámbulo, en primer lugar, y en relación con las instituciones de la Comunidad Foral de Navarra (título I), se adecua la regulación de las tres Instituciones Forales de Navarra ya reconocidas como tales por el artículo 10 del Amejoramiento (en particular del Parlamento de Navarra y del Presidente del Gobierno de Navarra, que pasa a configurarse como Presidente de la Comunidad Foral), y se introduce en dicho texto una mención expresa tanto al Defensor del Pueblo de Navarra como al Consejo de Navarra, que por su rango, relevancia y funciones, se considera deben tener cabida en el mismo.

De entre las modificaciones operadas en el título I merece destacarse la del artículo 30, con el objetivo de romper el límite del transcurso del término natural 
de la legislatura para el mandato del nuevo Parlamento elegido como consecuencia de la disolución anticipada del anterior por decisión del Presidente de la Comunidad Foral de Navarra, aumentándolo al término ordinario de una nueva legislatura completa (cuatro años); facultad de disolución anticipada que le fue atribuida al Presidente por la única reforma operada hasta la fecha en el Amejoramiento (Ley Orgánica 1/2001, de 26 de marzo).

En cuanto a las facultades y competencias de Navarra (título II), se adecua la terminología del año 1982 a la actualmente utilizada en el ordenamiento jurídico vigente, se suprime alguna figura jurídica ya inexistente, se introduce en el Amejoramiento una expresa referencia al Presidente del Tribunal Superior de Justicia de Navarra y a la Fiscalía Superior de la Comunidad Foral de Navarra, se da un contenido sustantivo a la actuación exterior de la Comunidad Foral y sus relaciones con la Unión Europea, y se perfilan mejor las funciones de la Junta de Cooperación.

Finalmente, y desde un punto de vista estrictamente técnico, se derogan cuatro disposiciones transitorias (primera, segunda, quinta y sexta), por haber sido ya cumplidos debidamente los mandatos en ellas contenidos.

En segundo lugar, se aprobaron las siguiente Leyes sobre cesión de tributos a las Comunidades Autónomas:

Ley 16/2010, de 16 de julio, del régimen de cesión de tributos del Estado a la Comunidad Autónoma de Cataluña y de fijación del alcance y condiciones de dicha cesión; Ley 17/2010, de 16 de julio, del régimen de cesión de tributos del Estado a la Comunidad Autónoma de Galicia y de fijación del alcance y condiciones de dicha cesión; Ley 18/2010, de 16 de julio, del régimen de cesión de tributos del Estado a la Comunidad Autónoma de Andalucía y de fijación del alcance y condiciones de dicha cesión; Ley 19/2010, de 16 de julio, del régimen de cesión de tributos del Estado a la Comunidad Autónoma del Principado de Asturias y de fijación del alcance y condiciones de dicha cesión; Ley 20/2010, de 16 de julio, del régimen de cesión de tributos del Estado a la Comunidad Autónoma de Cantabria y de fijación del alcance y condiciones de dicha cesión; Ley 21/2010, de 16 de julio, del régimen de cesión de tributos del Estado a la Comunidad Autónoma de La Rioja y de fijación del alcance y condiciones de dicha cesión; Ley 22/2010, de 16 de julio, del régimen de cesión de tributos del Estado a la Comunidad Autónoma de la Región de Murcia y de fijación del alcance y condiciones de dicha cesión Ley 23/2010, de 16 de julio, del régimen de cesión de tributos del Estado a la Comunitat Valenciana y de fijación del alcance y condiciones de dicha cesión; Ley 24/2010, de 16 de julio, del régimen de cesión de tributos del Estado a la Comunidad Autónoma de Aragón y de fijación del alcance y condiciones de dicha cesión; Ley 25/2010, de 16 de julio, del régimen de cesión de tributos del Estado a la Comunidad Autónoma de Castilla-La Mancha y de fijación del alcance y condiciones 
de dicha cesión; Ley 26/2010, de 16 de julio, del régimen de cesión de tributos del Estado a la Comunidad Autónoma de Canarias y de fijación del alcance y condiciones de dicha cesión; Ley 27/2010, de 16 de julio, del régimen de cesión de tributos del Estado a la Comunidad Autónoma de Extremadura y de fijación del alcance y condiciones de dicha cesión; Ley 28/2010, de 16 de julio, del régimen de cesión de tributos del Estado a la Comunidad Autónoma de las Illes Balears y de fijación del alcance y condiciones de dicha cesión; Ley 29/2010, de 16 de julio, del régimen de cesión de tributos del Estado a la Comunidad de Madrid y de fijación del alcance y condiciones de dicha cesión, y Ley 30/2010, de 16 de julio, del régimen de cesión de tributos del Estado a la Comunidad de Castilla y León y de fijación del alcance y condiciones de dicha cesión.

Como se indica en la Exposición de Motivos de estas leyes, el nuevo sistema de financiación autonómica se estructura en torno a varios ejes básicos: el refuerzo del Estado del Bienestar en el marco de la estabilidad presupuestaria; el incremento de la equidad y la suficiencia en la financiación del conjunto de las competencias autonómicas; el aumento de la autonomía y de la corresponsabilidad; y por último, la mejora de la dinámica y estabilidad del sistema.

Como consecuencia de la profundización en el principio de corresponsabilidad fiscal, el régimen de cesión de tributos se ve afectado de tal manera que se amplían los porcentajes de cesión y las competencias normativas de las Comunidades Autónomas en los tributos que son objeto de cesión parcial. Respecto a la ampliación de los porcentajes de cesión, se produce una elevación del porcentaje de cesión del Impuesto sobre la Renta de las Personas Físicas del 33 por ciento al 50 por ciento, del Impuesto sobre el Valor Añadido del 35 por ciento al 50 por ciento y de los Impuestos Especiales de Fabricación sobre la Cerveza, el Vino y Bebidas Fermentadas, Productos Intermedios, Alcohol y Bebidas Derivadas, Hidrocarburos y Labores del Tabaco del 40 por ciento al 58 por ciento.

Por otro lado, se amplían las competencias en el Impuesto sobre la Renta de las Personas Físicas, incorporando novedosamente la posibilidad de modificación de los mínimos personales y familiares, así como permitiendo mayores márgenes en la aprobación de la escala autonómica y deducciones de la cuota. En cuanto al Impuesto sobre el Valor Añadido, el Gobierno se ha comprometido a trabajar con las instituciones de la Unión Europea para que las normas comunitarias permitan el ejercicio de capacidad normativa de las Comunidades Autónomas en la fase minorista del impuesto con destino exclusivo a los consumidores finales.

Finalmente, el Gobierno se ha comprometido, en el marco del actual procedimiento de la Comisión Europea sobre el Impuesto sobre las Ventas Minoristas de Determinados Hidrocarburos (en adelante, IVMDH), a proponer la modificación de la Directiva 2003/96/CE del Consejo, de 27 de octubre de 2003, por la 
que se reestructura el marco comunitario de imposición de los productos energéticos y de la electricidad, para que, si eventualmente fuera necesario, pueda sustituirse este impuesto por suplementos autonómicos de tipos sobre determinados productos sujetos al Impuesto sobre Hidrocarburos, con neutralidad financiera.

Finalmente, se aprobó la Ley Ley 44/2010, de 30 de diciembre, de aguas canarias, cuyo artículo único dispone:

1. Entre los puntos extremos más salientes de las islas e islotes que integran, según el artículo 2 de su Estatuto de Autonomía, el Archipiélago canario, se trazará un contorno perimetral que siga la configuración general del archipiélago, tal como se establece en el Anexo de esta Ley. Las aguas que queden integradas dentro de este contorno perimetral recibirán la denominación de aguas canarias y constituyen el especial ámbito marítimo de la Comunidad Autónoma de Canarias. 2. El ejercicio de las competencias estatales o autonómicas sobre las aguas canarias y, en su caso, sobre los restantes espacios marítimos que rodean a Canarias sobre los que el Estado español ejerza soberanía o jurisdicción se realizará teniendo en cuenta la distribución material de competencias establecidas constitucional y estatutariamente tanto para dichos espacios como para los terrestres.

Respecto al control de constitucionalidad de normas autonómicas y a los conflictos de competencias pueden citarse las siguientes sentencias:

1.- La Sentencia 65/2010, de 18 de octubre, desestimó el conflicto positivo de competencia interpuesto por el Gobierno de Aragón en relación con el Real Decreto 1229/2005, de 13 de octubre, por el que se regulan las subvenciones públicas con cargo a los presupuestos generales del Estado en áreas de influencia socioeconómica de los parques nacionales. No es constitucionalmente necesario que las subvenciones estén vinculadas a la ejecución de un plan director y las subvenciones controvertidas fueron adecuadamente territorializadas al dejar un margen a las Comunidades Autónomas para concretar su afectación o destino o, al menos, para desarrollar y completar la regulación de las condiciones de otorgamiento de las ayudas y su tramitación.

2.- La STC 88/2010, de 15 de noviembre, declaró la inconstitucionalidad del art. 15.6 de la Ley 1/2002, de 26 de febrero, del comercio de Cantabria, por causas competenciales. El legislador autonómico había introducido un requisito, que no figuraba en la normativa básica estatal, para que los establecimientos comerciales pudieran acogerse a la liberalización de horarios prevista para las zonas turísticas. Esa inclusión contradecía el régimen de libertad de horarios comerciales establecido por la normativa básica estatal.

3.- La STC 113/2010, de 24 de noviembre, enjuició la constitucionalidad de dos disposiciones de la Ley del Parlamento de Canarias 8/1999, de 27 de abril, de creación de las escalas de profesores numerarios y maestros de taller de for- 
mación profesional marítimo-pesquera. Ambas disposiciones introducían sendas dispensas de titulación: en el caso de la integración de funcionarios transferidos en las escalas de la función pública autonómica, el Tribunal declaró que la norma enjuiciada no contravenía las bases del régimen estatutario de los funcionarios públicos establecidas por el Estado ex art. 149.1.18 CE; en cambio, la norma que transformaba en funcionario de carrera al personal interno era inconstitucional, pues desconocía los principios de mérito y capacidad.

5.- La Sentencia 129/2010, de 29 de noviembre, estimó parcialmente el conflicto positivo de competencia interpuesto por el Consejo de Gobierno de la Comunidad de Madrid respecto del Real Decreto 1472/2007, de 2 de noviembre, por el que se regula la renta básica de emancipación de los jóvenes, al entender que la retención por el Estado de algunas de las facultades de gestión de estas ayudas previstas en la norma reglamentaria no se justifican en la necesidad de homogeneizar la gestión resultante de las limitaciones presupuestarias ni representan una garantía de la igualdad de trato de los solicitantes.

5.- La STC 130/2010, de 29 de noviembre, anuló otro precepto de la Ley de comercio de Cantabria, el art. $31 \mathrm{~b}$ ), limitativo de las ventas promocionales al cuarenta por ciento de los artículos existentes en el establecimiento. Esta previsión no se encuadra en el título competencial «comercio interior» invocado por la Comunidad Autónoma, que debe tener como principal objetivo la defensa y beneficio del consumidor, sino en el de defensa de la competencia, cuya titularidad corresponde al Estado ex art. 149.1.13 CE.

\section{DERECHOS, DEBERES Y LIBERTADES}

En primer lugar, y por seguir la ubicación de las materias en el articulado de la Constitución, ha de mencionarse, en materia de igualdad, la STC 9/2010, de 27 de abril, que estimó un recurso de amparo por entender que una decisión judicial había vulnerado el derecho a la igualdad y a no sufrir discriminación por razón de nacimiento: en dicha resolución se excluyó que los hijos adoptados no se incluían dentro de los legítimos al interpretar las disposiciones de un testamento otorgado en 1927. Al no aplicar una interpretación que elimine una desigualdad injustificada se está lesionando el derecho a la igualdad, en la línea señalada en la sentencia del Tribunal Europeo de Derechos Humanos en el caso Pla y Puncernau c. Andorra.

Respecto a la protección de la vida y la integridad física se aprobó la Ley Orgánica $2 / 2010$, de 3 de marzo, de salud sexual y reproductiva y de la interrupción voluntaria del embarazo, con el objeto (art. 1) de garantizar los derechos funda- 
mentales en el ámbito de la salud sexual y reproductiva, regular las condiciones de la interrupción voluntaria del embarazo y establecer las correspondientes obligaciones de los poderes públicos. En dicha Ley se reconoce el derecho a la maternidad libremente decidida (art. 2).

En lo que se refiere a la interrupción voluntaria del embarazo, son requisitos necesarios (art. 13): que se practique por un médico especialista o bajo su dirección; que se lleve a cabo en centro sanitario público o privado acreditado; que se realice con el consentimiento expreso y por escrito de la mujer embarazada o, en su caso, del representante legal, de conformidad con lo establecido en la Ley 41/2002, Básica Reguladora de la Autonomía del Paciente y de Derechos y Obligaciones en materia de información y documentación clínica. Podrá prescindirse del consentimiento expreso en el supuesto previsto en el artículo 9.2.b) de la referida Ley.

En el caso de las mujeres de 16 y 17 años, el consentimiento para la interrupción voluntaria del embarazo les corresponde exclusivamente a ellas de acuerdo con el régimen general aplicable a las mujeres mayores de edad. Al menos uno de los representantes legales, padre o madre, personas con patria potestad o tutores de las mujeres comprendidas en esas edades deberá ser informado de la decisión de la mujer. Se prescindirá de esta información cuando la menor alegue fundadamente que esto le provocará un conflicto grave, manifestado en el peligro cierto de violencia intrafamiliar, amenazas, coacciones, malos tratos, o se produzca una situación de desarraigo o desamparo.

Podrá interrumpirse el embarazo dentro de las primeras catorce semanas de gestación a petición de la embarazada, siempre que concurran los requisitos siguientes (art. 14): a) Que se haya informado a la mujer embarazada sobre los derechos, prestaciones y ayudas públicas de apoyo a la maternidad,... b) Que haya transcurrido un plazo de al menos tres días, desde la información mencionada en el párrafo anterior y la realización de la intervención.

Excepcionalmente (art. 15), podrá interrumpirse el embarazo por causas médicas cuando concurra alguna de las circunstancias siguientes: a) Que no se superen las veintidós semanas de gestación y siempre que exista grave riesgo para la vida o la salud de la embarazada y así conste en un dictamen emitido con anterioridad a la intervención por un médico o médica especialista distinto del que la practique o dirija. En caso de urgencia por riesgo vital para la gestante podrá prescindirse del dictamen. b) Que no se superen las veintidós semanas de gestación y siempre que exista riesgo de graves anomalías en el feto y así conste en un dictamen emitido con anterioridad a la intervención por dos médicos especialistas distintos del que la practique o dirija. c) Cuando se detecten anomalías fetales incompatibles con la vida y así conste en un dictamen emitido con anterioridad por un médico o médica especialista, distinto del que practique la intervención, o 
cuando se detecte en el feto una enfermedad extremadamente grave e incurable en el momento del diagnóstico y así lo confirme un comité clínico.

El artículo 145 del Código Penal queda redactado de la forma siguiente: 1. El que produzca el aborto de una mujer, con su consentimiento, fuera de los casos permitidos por la ley será castigado con la pena de prisión de uno a tres años e inhabilitación especial para ejercer cualquier profesión sanitaria, o para prestar servicios de toda índole en clínicas, establecimientos o consultorios ginecológicos, públicos o privados, por tiempo de uno a seis años. El juez podrá imponer la pena en su mitad superior cuando los actos descritos en este apartado se realicen fuera de un centro o establecimiento público o privado acreditado. 2. La mujer que produjere su aborto o consintiere que otra persona se lo cause, fuera de los casos permitidos por la ley, será castigada con la pena de multa de seis a veinticuatro meses. 3. En todo caso, el juez o tribunal impondrá las penas respectivamente previstas en este artículo en su mitad superior cuando la conducta se llevare a cabo a partir de la vigésimo segunda semana de gestación.

Se añade un nuevo artículo 145 bis del Código Penal, que tendrá la siguiente redacción: 1 . Será castigado con la pena de multa de seis a doce meses e inhabilitación especial para prestar servicios de toda índole en clínicas, establecimientos o consultorios ginecológicos, públicos o privados, por tiempo de seis meses a dos años, el que dentro de los casos contemplados en la ley, practique un aborto: a) sin haber comprobado que la mujer haya recibido la información previa relativa a los derechos, prestaciones y ayudas públicas de apoyo a la maternidad; b) sin haber transcurrido el período de espera contemplado en la legislación; c) sin contar con los dictámenes previos preceptivos; d) fuera de un centro o establecimiento público o privado acreditado. En este caso, el juez podrá imponer la pena en su mitad superior. 2. En todo caso, el juez o tribunal impondrá las penas previstas en este artículo en su mitad superior cuando el aborto se haya practicado a partir de la vigésimo segunda semana de gestación. 3. La embarazada no será penada a tenor de este precepto.

Se suprime el inciso « 417 bis» de la letra a) del apartado primero de la disposición derogatoria única.

El apartado 4 del artículo 9 de la Ley 41/2002, de 14 de noviembre, Básica Reguladora de la Autonomía del Paciente y de Derechos y Obligaciones en materia de información y documentación clínica, tendrá la siguiente redacción: La práctica de ensayos clínicos y de técnicas de reproducción humana asistida se rige por lo establecido con carácter general sobre la mayoría de edad y por las disposiciones especiales de aplicación.

En el ámbito jurisprudencial, las SSTC 40/2010, de 19 de julio, y 63/2010, de 18 de octubre, aplicaron la doctrina relativa a las exigencias derivadas del derecho a la tutela judicial efectiva en relación con las decisiones judiciales de so- 
breseimiento y archivo de causas penales incoadas por denuncias de torturas o de tratos inhumanos o degradantes que, siguiendo la establecida por el Tribunal Europeo de Derechos Humanos, reclama un especial celo de los órganos judiciales a quienes corresponda tramitar esas denuncias.

El derecho a la tutela judicial efectiva en este ámbito se vulnera cuando no se abre o se clausura la instrucción pese a la existencia de sospechas razonables - $\mathrm{y}$ susceptibles de ser despejadas - de que se hayan podido producir los ilícitos denunciados. De los acuerdos internacionales firmados por España y del propio tenor del artículo 15 de la Constitución se infiere un especial mandato de agotar cuantas posibilidades razonables de indagación resulten útiles para aclarar los hechos. Para valorar si la decisión judicial de archivar las diligencias abiertas vulnera las exigencias de la tutela judicial efectiva hay que atender a las circunstancias concretas de cada caso, teniendo siempre presente la escasez de pruebas que de ordinario existen en este tipo de delitos.

Sobre libertad personal y seguridad, la Ley Orgánica 5/2010, de 22 de junio, modificó la Ley Orgánica 10/1995, de 23 de noviembre, del Código Penal; esta amplia modificación se refiere, entre otras materias y según su Preámbulo, a las siguientes:

En materia de circunstancias modificativas de la responsabilidad criminal se ha considerado conveniente otorgar carta de naturaleza legal a la circunstancia atenuante de dilaciones indebidas. Se exige para su apreciación que el retraso en la tramitación tenga carácter extraordinario, que no guarde proporción con la complejidad de la causa y que no sea atribuible a la conducta del propio imputado. De esta manera se recogen los elementos fundamentales de la jurisprudencia del Tribunal Supremo, que ha construido esta circunstancia como atenuante por analogía...

De conformidad con los principios que orientan la reforma, se procede a la modificación del artículo 36. De esta forma, para los casos de penas privativas de libertad superiores a cinco años, la exigencia de cumplimiento de al menos la mitad de la condena antes de poder obtener la clasificación en tercer grado se establece en el caso de delitos cometidos contra la libertad e indemnidad sexual de menores de trece años, delitos referentes a organizaciones y grupos terroristas y delitos de terrorismo, así como los delitos cometidos en el seno de una organización o grupo criminal. Esta modificación, que se estima conveniente para estos grupos de delitos de extrema gravedad, se considera por el contrario innecesaria como régimen general respecto de todos los delitos sancionados con penas de prisión superiores a cinco años. Por esta razón se elimina el automatismo hasta ahora vigente, introduciendo un mecanismo más flexible que permita a los jueces y tribunales adecuar la responsabilidad criminal a la gravedad del hecho y a la personalidad del delincuente. Así, la remodelación del llamado «periodo de seguri- 
dad» garantiza la primordial finalidad constitucional de la pena, la resocialización, sin que por otra parte ello comporte detrimento alguno en la persecución por el Estado de otros fines legítimos de la misma...

la presente Ley introduce, mediante la modificación parcial y una leve reordenación del Título IV del Libro Primero del Código Penal, una nueva medida denominada libertad vigilada, que se inserta naturalmente en el régimen general de dichas medidas de seguridad, algunas de las cuales se integran y refunden en ese concepto común (artículo 106)... Así, la libertad vigilada es una medida de seguridad que el Tribunal impone, de manera facultativa o preceptiva, según la propia norma señala en cada caso, y cuyo contenido se concreta en una serie de limitaciones, obligaciones, prohibiciones o reglas de conducta, aplicables separada o conjuntamente, dentro de los márgenes de duración específicos que en su caso resulten de la parte especial del Código, tendentes no solo a la protección a las víctimas, sino también a la rehabilitación y la reinserción social del delincuente, objetivo que preside toda la reforma. Y que puede modificarse, ya en fase de ejecución, atendiendo a la evolución del sujeto y mediante un sencillo trámite que se caracteriza por un reforzamiento de la garantía de contradicción, que alcanza incluso a las víctimas que no sean parte en el proceso.

La novedad sustancial que incorpora la libertad vigilada es que resulta aplicable no sólo cuando el pronóstico de peligrosidad del individuo se relaciona con estados patológicos que han determinado su inimputabilidad o semiinimputabilidad, sino también cuando la peligrosidad deriva del específico pronóstico del sujeto imputable en relación con la naturaleza del hecho cometido, siempre y cuando el propio legislador así lo haya previsto de manera expresa. En estos casos, tal y como resulta del nuevo artículo 106.2, la medida no se establece, por obvias razones, con carácter alternativo a la pena de prisión o para su ejecución previa a ésta, sino que se impone en sentencia junto a la pena privativa de libertad para su ejecución posterior a la excarcelación, y se hará o no efectiva justamente en función de ese pronóstico de peligrosidad, formulado cuando se acerca dicho momento extintivo de la pena y reconsiderado después con cadencia como mínimo anual (artículo 98.1)...

Para solucionar los problemas interpretativos surgidos acerca de cuál es el procedimiento penal donde debe abonarse el tiempo de prisión provisional sufrido por un imputado que al mismo tiempo está cumpliendo una pena de privación de libertad impuesta en otra causa, se procede a la modificación del artículo 58 para dejar claro que en esos supuestos solamente será de abono el tiempo de prisión realmente sufrido en la liquidación de condena referente a la pena que esté cumpliendo...

Para la fijación de la responsabilidad de las personas jurídicas se ha optado por establecer una doble vía. Junto a la imputación de aquellos delitos cometidos en su nombre o por su cuenta, y en su provecho, por las personas que tienen poder de 
representación en las mismas, se añade la responsabilidad por aquellas infracciones propiciadas por no haber ejercido la persona jurídica el debido control sobre sus empleados, naturalmente con la imprescindible consideración de las circunstancias del caso concreto a efectos de evitar una lectura meramente objetiva de esta regla de imputación...

En el ámbito de la prescripción del delito, con el objetivo de aumentar la seguridad jurídica, se ha optado por una regulación detallada del instituto que ponga fin a las diferencias interpretativas surgidas en los últimos tiempos. Para llevar a cabo esta tarea, se ha prestado especial atención a la necesidad de precisar el momento de inicio de la interrupción de la prescripción, estableciéndose que ésta se produce, quedando sin efecto el tiempo transcurrido, cuando el procedimiento se dirija contra persona determinada que aparezca indiciariamente como penalmente responsable. Para entender que ello ocurre se requiere, cuando menos, una actuación material del Juez Instructor...

Como respuesta al fenómeno cada vez más extendido de la compraventa de órganos humanos y al llamamiento de diversos foros internacionales a abordar su punición, se ha incorporado como infracción penal la obtención o el tráfico ilícito de órganos humanos, así como el trasplante de los mismos...

[en relación con el acoso laboral se entiende], por tal el hostigamiento psicológico u hostil en el marco de cualquier actividad laboral o funcionarial que humille al que lo sufre, imponiendo situaciones de grave ofensa a la dignidad. Con ello quedarían incorporadas en el tipo penal todas aquellas conductas de acoso producidas tanto en el ámbito de las relaciones jurídico privadas como en el de las relaciones jurídico-públicas...

Igualmente, al hilo de la proliferación, durante la última década, de conductas acosadoras en la esfera de la vivienda, se sanciona también el acoso inmobiliario. Con ello se pretende tutelar el derecho al disfrute de la vivienda por parte de propietarios o inquilinos frente a los ataques dirigidos a obligar a unos o a otros a abandonarla para así alcanzar, en la mayoría de los casos, objetivos especuladores. Distintos pronunciamientos judiciales habían venido poniendo de manifiesto las dificultades que para la represión de estas conductas se derivaba de la ausencia hasta el momento de una específica regulación penal de este fenómeno...

El tratamiento penal unificado de los delitos de trata de seres humanos e inmigración clandestina que contenía el artículo 318 bis resultaba a todas luces inadecuado, en vista de las grandes diferencias que existen entre ambos fenómenos delictivos. La separación de la regulación de estas dos realidades resulta imprescindible tanto para cumplir con los mandatos de los compromisos internacionales como para poner fin a los constantes conflictos interpretativos...

Para llevar a cabo este objetivo se procede a la creación del Título VII bis, denominado «De la trata de seres humanos». Así, el artículo 177 bis tipifica un de- 
lito en el que prevalece la protección de la dignidad y la libertad de los sujetos pasivos que la sufren. Por otro lado, resulta fundamental resaltar que no estamos ante un delito que pueda ser cometido exclusivamente contra personas extranjeras, sino que abarcará todas las formas de trata de seres humanos, nacionales o trasnacionales, relacionadas o no con la delincuencia organizada. En cambio, el delito de inmigración clandestina siempre tendrá carácter trasnacional, predominando, en este caso, la defensa de los intereses del Estado en el control de los flujos migratorios...

El agravamiento penológico operado por la Ley Orgánica 15/2003, de 25 de noviembre, en el ámbito de los delitos relativos a la propiedad intelectual e industrial ha evidenciado una cierta quiebra de la necesaria proporcionalidad de la pena en el caso de conductas consistentes en la venta a pequeña escala de copias fraudulentas de obras amparadas por tales derechos, máxime cuando frecuentemente los autores de este tipo de conductas son personas en situaciones de pobreza, a veces utilizados por organizaciones criminales, que con tales actos aspiran a alcanzar ingresos mínimos de subsistencia. Por ello, añadiendo un párrafo segundo al apartado 1 del artículo 270 y modificando el apartado 2 del artículo 274, para aquellos casos de distribución al por menor de escasa trascendencia, atendidas las características del culpable y la reducida cuantía del beneficio económico obtenido por éste, siempre que no concurra ninguna de las circunstancias de agravación que el propio Código Penal prevé, se opta por señalar penas de multa o trabajos en beneficio de la comunidad. Además, en tales supuestos, cuando el beneficio no alcance los 400 euros la conducta se castigará como falta.

Además, se aprobó la Ley 10/2010, de 28 de abril, de prevención del blanqueo de capitales y de la financiación del terrorismo.

En el ámbito jurisprudencial, las Sentencias 37/2010, de 19 de julio, y 59/2010, de 4 de octubre, otorgaron el amparo respecto de dos sentencias penales que efectuaron una interpretación de la legislación aplicable en materia de prescripción de los delitos centrada exclusivamente en la fecha en que las denuncias se habían registrado en los Juzgados y sin tomar en consideración el momento en el que se produjeron actos de interposición judicial para dirigir el procedimiento contra el culpable.

La Sentencia 122/2010, de 29 de noviembre, resolvió el recurso de amparo en el que se promovió la cuestión interna de inconstitucionalidad que dio lugar a la STC 73/2010, de 18 de octubre. Como ya se ha indicado, esta resolución llevó a cabo una interpretación conforme con la Constitución de las disposiciones del régimen disciplinario de la Guardia Civil que prevén la imposición de sanciones privativas de libertad ciñendo su alcance a aquellos supuestos en los que los miembros de este Cuerpo actuaran en el ejercicio de funciones militares y así se 
hiciera constar en la correspondiente resolución sancionadora. No era éste el caso de la sanción impugnada en la STC 122/2010, donde el relato de hechos hacía referencia a la falta de exacto cumplimiento de las órdenes recibidas en el curso de la investigación de un hecho delictivo, lo que condujo al otorgamiento del amparo.

En la Sentencia 143/2010, de 21 de diciembre, se concedió el amparo frente a un auto que acordó la adopción de una medida cautelar personal, como es la prisión provisional, que le fue notificada al interesado mediante una escueta reproducción de la parte dispositiva del auto. El hecho de que las actuaciones se hayan declarado secretas no es óbice para que la notificación incorpore una referencia, por sucinta que sea, al fin que legitima constitucionalmente la imposición de la medida y a las circunstancias concretas del caso.

En cuanto al secreto de las comunicaciones, las Sentencias 5/2010, de 7 de abril; 26/2010, de 27 de abril; 68/2010 y 72/2010, de 18 de octubre, reiteraron que su garantía jurisdiccional no se satisface plenamente con una autorización judicial de intervención de las mismas, sino que ésta ha de dictarse en el seno de un proceso, único cauce que permite controlar la propia actuación judicial. Cuando la medida se adopta en unas «diligencias indeterminadas», resulta contrario a las exigencias de control de la intervención la falta de notificación al Ministerio público de los autos de intervención o prórroga porque impide el control inicial del desarrollo y cese de la medida por el garante de los derechos de los ciudadanos.

En relación con los derechos del artículo 20, en el ámbito legislativo se aprobó la Ley 7/2010, de 31 de marzo, General de la Comunicación Audiovisual, que, según su Preámbulo,

pretende compendiar la normativa vigente aún válida, actualizar aquellos aspectos que han sufrido importantes modificaciones y regular las nuevas situaciones carentes de marco legal. Y todo ello con la misión de dar seguridad jurídica a la industria y posibilitar la creación de grupos empresariales audiovisuales con capacidad de competir en el mercado europeo y la apertura regulada de nuevos modelos de negocio como son la TDT de pago, la Alta Definición y la TV en Movilidad; y hacerlo garantizando también, el pluralismo y la protección de los derechos ciudadanos; al mismo tiempo que se fijan unas reglas de transparencia y competencia claras en un contexto de convivencia del sector público con el privado y de liberalización de la actividad audiovisual.

Así el Capítulo I del Título II esta consagrado íntegramente a la garantía de los derechos de los ciudadanos a recibir comunicación audiovisual en condiciones de pluralismo cultural y lingüístico — lo que implica la protección de las obras audiovisuales europeas y españolas en sus distintas lenguas—, así como a exigir 
ante las autoridades la adecuación de los contenidos al ordenamiento constitucional vigente. Este capítulo trata de forma individualizada las obligaciones de los prestadores de servicios de comunicación audiovisual en relación a los menores y personas con discapacidad que merecen a juicio del legislador y de las instituciones europeas una protección especial.

En el Capítulo II de este Título II se incluyen los derechos de los prestadores del servicio de comunicación audiovisual que básicamente son el de prestar ese servicio en condiciones de libertad en cuanto a selección de contenidos, línea editorial y emisión de canales. Libertad absoluta en el caso de las comunicaciones electrónicas. La posibilidad y condiciones de autorregulación y de emisión de contenidos publicitarios constituyen otros dos grandes apartados de derechos que se consagran en esta ley.

La regulación de la publicidad, conforme a los criterios establecidos por la Directiva Comunitaria ya citada, ocupa una parte importante de esta Ley. Está concebida como un instrumento de protección del consumidor frente a la emisión de mensajes publicitarios en todas sus formas en cuanto a tiempo y contenidos pero también con una normativa reguladora básica para impedir abusos e interpretaciones divergentes que han llevado, en el pasado, a la apertura de expedientes y discrepancias serias a la hora de interpretar los preceptos europeos. Y que, con esta Ley se pretende acabar al plantear un escenario claro e inequívoco alineado con la terminología y los postulados de la Comisión y el Parlamento Europeo. Finalmente este Título II dedica un capítulo a la regulación de los derechos sobre contenidos en régimen de exclusividad en la que se protege el derecho a la información de todos los ciudadanos como derecho prioritario y se fijan límites a la exclusividad en función de criterios de interés general que aseguran la emisión en abierto de una serie de acontecimientos relacionados fundamentalmente con eventos deportivos de gran audiencia y valor. Para ello, se incluye una referencia normativa básica siguiendo los criterios, resoluciones y recomendaciones de las autoridades y organismos de vigilancia de la competencia españoles y europeos.

El Título III parte del principio de libertad de empresa y establece el régimen jurídico básico para la prestación de un servicio de comunicación audiovisual, diferenciando aquellos que sólo precisan de comunicación previa por estar su segmento liberalizado, de aquellos otros que por utilizar espacio radioeléctrico público a través de ondas hertzianas y tener capacidad limitada necesitan de licencia previa otorgada en concurso público celebrado en las condiciones que fija esta misma Ley.

El Título III finaliza con un conjunto de artículos destinados a garantizar el pluralismo y la libre competencia en el mercado radiofónico y televisivo dada la importancia que tienen estos medios en la formación de la opinión pública. Se re- 
conoce el derecho a poseer participaciones significativas en varios prestadores de servicios estatales de comunicación, pero se limita ese derecho si en el momento de la fusión o compra de acciones se acumula más del $27 \%$ de la audiencia. Se ha optado por el criterio de audiencias a la hora de evaluar posiciones de dominio en el mercado siguiendo las soluciones recogidas por la más reciente legislación de los países europeos en la materia.

El Título IV se ocupa íntegramente de la normativa básica del Servicio Público de radio, televisión y oferta interactiva, respetando el sistema competencial fijado en la Constitución Española. En concreto, se refiere a los objetivos generales que debe buscar este servicio público como son: difundir contenidos que fomenten los valores constitucionales, la formación de opinión pública plural, la diversidad lingüística y cultural y la difusión del conocimiento y las artes, así como la atención a las minorías. Los objetivos deberán concretarse cada nueve años por los Parlamentos u órganos similares a nivel autonómico y local...

Y es la creación y regulación de la Autoridad Audiovisual estatal la que ocupa el Título V de esta Ley. El Consejo Estatal de Medios Audiovisuales (CEMA) será el órgano regulador y supervisor del sector que ejercerá sus competencias bajo el principio de independencia de los poderes políticos y económicos. Tendrá poder sancionador y sus miembros serán elegidos por mayoría cualificada de tres quintos del Congreso de los Diputados. Serán sus funciones principales garantizar la transparencia y el pluralismo en el sector y la independencia e imparcialidad de los medios públicos así como del cumplimiento de su función de servicio público. Se crea, asimismo, un Comité Consultivo de apoyo que garantice la participación de colectivos y asociaciones ciudadanas. Cierra el articulado el Título VI que contempla el régimen sancionador.

En materia jurisprudencial, la Sentencia 23/2010, de 27 de abril, tras constatar que la generalización de las nuevas tecnologías de tratamiento de la imagen permite calificar como caricaturas las alteraciones de fotografías originales, siempre que prime la creación irónica basada en la reelaboración de la fisonomía del modelo que tiene por objeto, cuando la caricatura se elabora mediante la distorsión de la imagen fotográfica de una persona queda afectado su derecho a la propia imagen, si bien esa afección puede estar justificada por el legítimo ejercicio de la libertad de expresión, o incluso de creación artística.

En la Sentencia 34/2010, de 19 de julio, se otorgó el amparo frente a una resolución judicial que, en el seno de un proceso de acogimiento de un menor, había adoptado como medida cautelar la suspensión de emisión de un programa televisivo sobre la vida de ese mismo menor. El Tribunal concluyó que la medida había lesionado la libertad de información porque se adoptó sin las garantías y al margen de los procedimientos específicamente previstos por la ley habilitante 
—la Ley Orgánica 1/1982, de 5 de mayo, de protección civil del derecho al honor, a la intimidad personal y familiar y a la propia imagen- para asegurar la correcta protección de todos los derechos en presencia.

La Sentencia 89/2010, de 15 de noviembre, amparó al demandante, propietario de un restaurante que había sido condenado por un delito de injurias graves con publicidad porque, en período electoral, había colocado en el interior de su establecimiento una serie de recortes de prensa y un pasquín crítico con la gestión del Alcalde de la localidad. Los órganos jurisdiccionales no habían ponderado adecuadamente el derecho fundamental ejercido por el acusado y tampoco habían tomado en consideración que las críticas se habían formulado contra el responsable del gobierno municipal en el curso de la campaña electoral.

A propósito del derecho de reunión y manifestación, la Sentencia 96/2010, de 15 de noviembre, reiteró jurisprudencia anterior de que resulta contraria al derecho proclamado en el artículo 21 de la Constitución la prohibición de reuniones y manifestaciones basándose en el solo hecho de que se convoquen en período electoral. Únicamente cuando se aporten razones fundadas sobre el carácter electoral de la manifestación, es decir, cuando la finalidad sea la captación de sufragios y haya sido convocada por partidos, federaciones, coaliciones o agrupaciones, únicas personas jurídicas que pueden realizar campaña electoral junto a sus candidatos según la legislación, podrá denegarse la autorización por dicho motivo. Por esta razón, se consideró lesionado el derecho por la decisión adoptada por la Junta Electoral Provincial de Sevilla de negar autorización para la celebración de una manifestación el día 8 de marzo de 20008, con el fin de conmemorar el día internacional de la mujer trabajadora, porque podría incidir en la neutralidad de la jornada de reflexión previa a las elecciones generales y autonómicas convocadas para el día siguiente.

En relación con los derechos de participación del artículo 23, ya se ha mencionado la Ley Orgánica 8/2010, de 4 de noviembre, de reforma de la Ley Orgánica 5/1985, de 19 de junio, del Régimen Electoral General, en relación con el voto al Senado.

En materia jurisprudencial, la Sentencia 33/2010, de 19 de julio, estimó contrarios a este derecho fundamental los acuerdos de la Mesa de las Cortes Valencianas que inadmitieron diversas iniciativas parlamentarias (preguntas y solicitud de comparecencia de una Consejera) sin justificación o motivación alguna, lo que impedía a los parlamentarios afectados conocer las razones de la decisión y restringía ilegítimamente los derechos y facultades que pertenecen al núcleo de las funciones representativas del cargo parlamentario previsto en el 23.2 de la Constitución. 
En la misma línea, la Sentencia 44/2010, de 26 de julio, concluyó que la decisión, también de la Mesa de las Cortes Valencianas, de inadmisión de una serie de preguntas parlamentarias y de una proposición no de ley, vulneraba igualmente este derecho.

En el amplísimo catálogo de la tutela judicial deben recordarse, en primer lugar, algunas de las sentencias del Tribunal Europeo de Derechos Humanos: en el asunto Tendam c. España, de 13 de julio, el Tribunal apreció lesión de los artículos 6.2 del CEDH y 1 del Protocolo $n^{\circ}$ 1: la decisión del Ministerio de Justicia de rechazar una indemnización alegando que el acusado fue absuelto por falta de pruebas y no por constatación de la inexistencia de los hechos delictivos ignoró que el demandante ha resultado absuelto, lo que debe ser acatado más allá de los motivos; además, el demandante no recuperó los bienes que se le habían incautado y al justificar la Administración de Justicia su desaparición y, en otros casos, su deterioro, los perjuicios causados le son imputables; en los asuntos Marcos Barrios c. España, de 21 de septiembre, y García Hernández c. España, de 16 de noviembre, se apreció vulneración del artículo 6: en el primer caso porque el demandante fue absuelto en primera instancia y condenado en apelación como autor de un delito de asesinato sin que se celebrara vista a pesar de que el tribunal de apelación modificó los hechos declarados probados en primera instancia; en el segundo caso las cuestiones analizadas en la apelación eran cuestiones de hecho, por lo que la condena de la demandante sin ser oída, tras haber sido absuelta en la instancia vulneró las exigencias del CEDH; en el caso Cardona Serrat c. España, de 26 de octubre, se consideró vulnerado el artículo 6.1 por falta de imparcialidad del tribunal juzgador. El TEDH concluyó que el demandante tenía motivos para entender que los magistrados que habían de juzgarle se habían formado ya una opinión sobre su culpabilidad.

En cuanto a las numerosas sentencias del Tribunal Constitucional que se han pronunciado sobre alguno de los derechos protegidos por el artículo 24 de la Constitución, mencionaremos únicamente algunas de las que consideramos más significativas:

Las Sentencias 37/2010, de 19 de julio; 59/2010, de 4 de octubre, y $95 / 2010$, de 15 de noviembre, otorgaron el amparo frente a sendas sentencias penales que no tutelaron el derecho a la libertad personal de los demandantes al interpretar la legislación vigente, pues al pronunciarse acerca de la prescripción de la responsabilidad penal habían tomado en cuenta exclusivamente la fecha en que las respectivas denuncias se habían registrado en los Juzgados, sin considerar el momento en el que se produjeron actos de interposición judicial para dirigir el procedimiento contra el culpable. 
Las SSTC 38/2010, de 19 de julio, y 67/2010, de 18 de octubre, otorgaron el amparo a sendos colegios profesionales que actuaron en defensa del interés de la profesión y del interés profesional de los colegiados. En la STC 139/2010, de 21 de diciembre, se reconoció legitimación no sólo de una asociación profesional sino también de un organismo público - la Autoridad Portuaria de Santa Cruz de Tenerife- para recurrir una orden ministerial que decidía el destino de unos bienes de titularidad estatal.

Las Sentencias 40/2010, de 19 de julio, y 63/2010, de 18 de octubre, otorgaron el amparo por vulneración del derecho a la tutela judicial efectiva en relación con el derecho a no ser sometido a tortura o tratos inhumanos o degradantes. En ambos supuestos los órganos judiciales que conocieron de las denuncias presentadas por quienes decían ser víctima de este tipo de tratos no habían agotado todos los medios razonables y eficaces de investigación a su alcance para desmentir o confirmar la credibilidad de la denuncia, pese a existir sospechas razonables al respecto.

En la Sentencia 58/2010, de 4 de octubre, se declaró que no puede presumirse, sin lesionar el derecho consagrado en el art. 24.1 CE, que las comunicaciones procesales realizadas por medios técnicos, entre ellos el fax, hayan llegado a conocimiento de la parte interesada cuando ésta discuta fundadamente la recepción de la comunicación o la fecha en que se produjo esa recepción.

En la Sentencia 69/2010, de 18 de octubre, se estimó una infracción del principio non bis in idem» de quienes, tras ser absueltos por sentencia firme de un delito de alzamiento de bienes, fueron luego procesados por estos mismos hechos por un órgano judicial distinto. El único elemento diferenciador entre ambos procesos penales eran las víctimas, lo que carece toda relevancia a la vista de la identidad del acto de disposición patrimonial sometido a enjuiciamiento.

En la Sentencia 71/2010, de 18 de octubre, se concluyó que vulneraron este derecho sendas resoluciones de la jurisdicción civil que apreciaron erróneamente la excepción de cosa juzgada material pese a que no mediaba identidad objetiva entre el proceso en el que los órganos judiciales entendieron que había recibido respuesta la pretensión (reclamación de indemnización) y aquel del que traía causa el recurso de amparo (reclamación de intereses de demora respecto de la cantidad a la que ascendía la indemnización otorgada).

Las Sentencias 75/2010 y 76/2010, de 19 de octubre, otorgaron el amparo a los trabajadores cuya relación laboral con la empresa para la que prestaban sus servicios cesó como consecuencia del ejercicio, entre otros, del derecho a la tutela judicial, lo que representó una quiebra de la garantía de indemnidad que se traduce en la imposibilidad de adoptar medidas de represalia derivadas de la realización por el trabajador de actuaciones tendentes a la tutela de sus derechos. 
La Sentencia 78/2010, de 20 de octubre, desestimó el recurso de amparo promovido por el Gobierno de Canarias alegando vulneración de los derechos a la tutela judicial efectiva y a un proceso con todas las garantías. El conocimiento del recurso fue avocado al Pleno con el fin de rectificar la doctrina establecida en la STC 194/2006, de 19 de junio, acerca del planteamiento de la cuestión prejudicial de Derecho comunitario europeo. Según la STC 78/2010, la obligación de plantearla desaparece, aun tratándose de órganos jurisdiccionales nacionales que no son susceptibles de un recurso judicial conforme al Derecho interno, tanto cuando la cuestión suscitada fuese materialmente idéntica a otra que haya sido objeto de una decisión prejudicial en caso análogo, como cuando la correcta aplicación del Derecho comunitario pueda imponerse con tal evidencia que no deje lugar a ninguna duda razonable sobre la solución de la cuestión. De modo que para dejar de aplicar una norma legal vigente por su contradicción con el Derecho comunitario el planteamiento de la cuestión prejudicial sólo resulta preciso, desde la perspectiva del art. $24 \mathrm{CE}$, en caso de que concurran los presupuestos fijados al efecto por el propio Derecho comunitario, cuya concurrencia corresponde apreciar a los Jueces y Tribunales de la jurisdicción ordinaria.

La Sentencia 94/2010, de 15 de noviembre, otorgó el amparo a quien denunció haber sido víctima de un delito de malos tratos y cuyo testimonio no fue valorado porque no se le había informado de la dispensa de la obligación de declarar a la que podía acogerse. El riguroso entendimiento realizado de esta dispensa resultó irrazonable por estar desconectado de su fundamento y finalidad, e hizo caso omiso de la continua y terminante actuación procesal de la recurrente, ignorando que la víctima de un delito tiene derecho a poner en marcha un proceso y a que éste se sustancie de conformidad con las reglas del proceso justo, en el que pueda obtener una respuesta razonable y fundada en Derecho.

En la Sentencia 123/2010, de 29 de noviembre, se declaró vulnerado el derecho a la tutela judicial efectiva en su vertiente de acceso al proceso de la Sociedad General de Autores y Editores de España (SGAE) al no ser llamada a un proceso en el que se reclamaba la devolución del importe pagado por canon de reproducción de copia privada, se controvertía el papel atribuido a las entidades gestora y se solicitaba el planteamiento de una cuestión de inconstitucionalidad en relación con ambos extremos.

En las SSTC 141/2010 y 142/2010, ambas de 21 de diciembre, se otorgó el amparo por un retraso de aproximadamente año y medio para la celebración de la vista de los respectivos procesos en materia de extranjería debido a razones estructurales. Ambas resoluciones insistieron en el interés que arriesga el demandante de amparo en el juicio que da origen al proceso constitucional: en el primero de ellas, la orden de expulsión del territorio nacional controvertida afectaba 
tanto al directamente concernido como a su familia y en el segundo, la inadmisión de la petición de asilo del recurrente determina que éste se encuentre en situación de ilegalidad en España y pueda verse impelido a abandonar el territorio nacional. Tratándose, en ambos casos, de retrasos de carácter estructural, el amparo otorgado fue exclusivamente declarativo pues la eventual anticipación del señalamiento para la vista de los respectivos recursos contencioso-administrativos podría agravar la situación de terceros ajenos al proceso constitucional y en atención al hecho de que el Tribunal Constitucional no puede entrar en los procesos estructurales de funcionamiento de la Administración de Justicia

En materia de legalidad sancionadora, se aprobó la Ley Orgánica 4/2010, de 20 de mayo, del Régimen disciplinario del Cuerpo Nacional de Policía.

En materia jurisprudencial, la STC 21/2010, de 27 de abril, anuló una sanción disciplinaria de postergación en la carrera impuesta a un notario pues aunque se encuentra prevista en el Reglamento notarial de 1944, su introducción en 1984 se llevó a cabo sin la necesaria cobertura legal y sin que se corresponda con la sanción de «traslación forzosa» contemplada en la norma reglamentaria preconstitucional pues los dos tipos de sanciones no son efectivamente homogéneas ni tienen las mismas consecuencias en la carrera profesional del sancionado.

La STC 57/2010, de 4 de octubre, apreció vulneración de los derechos a la tutela judicial y a la legalidad penal en las sentencias que condenaron al demandante de amparo por la comisión de cuatro delitos contra la hacienda pública porque la subsunción de la conducta enjuiciada en los tipos penales aplicados resultó irrazonable.

En la STC 73/2010, de 18 de octubre, la Sala Segunda del Tribunal resolvió una cuestión interna de inconstitucionalidad acerca de la eventual vulneración de los límites establecidos para la potestad sancionadora de la Administración civil por el art. 25.3 CE (prohibición de imposición de sanciones que impliquen privación de libertad) por los apartados 1 y 2 del art. 10 de la Ley Orgánica 11/1991, de régimen disciplinario de la Guardia Civil, que contempla la imposición de la sanción de arresto domiciliario para las infracciones leves y de arresto en establecimiento disciplinario militar para las infracciones graves. La Sala emitió un pronunciamiento de interpretación conforme, al declarar que lo dispuesto en los preceptos legales cuestionados sólo resulta acorde con la Constitución si se interpreta en el sentido de que la imposición de las sanciones privativas de libertad únicamente procede cuando la infracción haya sido cometida en una actuación estrictamente militar y así se motive en la resolución sancionadora.

La STC 124/2010, de 29 de noviembre, otorgó el amparo respecto de una sentencia de la Sala de lo Penal del Tribunal Supremo que aplicó una eximente completa de culpabilidad e impuso al acusado la medida de seguridad de inter- 
namiento en centro psiquiátrico por un máximo de veinte años, sin posibilidad de revisión hasta tanto hubieran transcurrido ocho años. Este último inciso es contrario al art. 25.1 CE porque desconoce que el Código penal establece con carácter obligatorio la revisión periódica anual.

En cuanto al derecho a la educación, la Sentencia 133/2010, de 2 de diciembre, desestimó el recurso interpuesto por unos padres que reivindicaban su derecho a educar a sus hijos menores de edad en el domicilio familiar. El Tribunal rechazó la pretensión ejercitada porque la facultad de los padres de elegir para sus hijos una educación ajena al sistema de escolarización obligatoria por motivos de orden pedagógico no está comprendida, ni siquiera prima facie, en ninguna de las libertades reconocidas en el art. $27 \mathrm{CE}$. Y, además, porque, incluso en el supuesto de que la decisión de no escolarizar a los hijos propios estuviera amparada en razones de orden moral o religioso y hallara acomodo en el contenido protegido por el art. 27.3 CE, el deber de escolarización de los niños de entre seis y dieciséis años ha sido expresamente impuesto por el legislador y encuentra plena justificación en otras determinaciones constitucionales.

Por lo que respecta a la libertad sindical, ya se han mencionado antes las sentencias 75/2010 y 76/2010, ambas de 19 de octubre, que iniciaron una serie compuesta por otras quince resoluciones (SSTC 98/2010 a 112/2010, todas de 16 de noviembre) en las que se declararon vulnerados los derechos a la tutela judicial y de huelga. Estas sentencias traían causa del despido de una serie de trabajadores como consecuencia de la resolución del contrato mercantil que unía a su empresa con una tercera, para la cual la primera prestaba actividades en régimen de subcontratación. Los amparos se otorgaron porque la resolución del contrato mercantil fue la respuesta empresarial al ejercicio de sus derechos fundamentales por los trabajadores de la empresa subcontratada, de modo que se encubría así una represalia por la actividad sindical y por la realización de actuaciones tendentes a la protección de los derechos e intereses legítimos de los propios trabajadores.

En materia tributaria se aprobó la Ley 2/2010, de 1 de marzo, por la que se trasponen determinadas Directivas en el ámbito de la imposición indirecta y se modifica la Ley del Impuesto sobre la Renta de no Residentes para adaptarla a la normativa comunitaria.

En cuanto a la libertad de empresa, se aprobaron la Ley 1/2010, de 1 de marzo, de reforma de la Ley 7/1996, de 15 de enero, de Ordenación del Comercio Minorista; la Ley 11/2010, de 28 de junio, de reforma del sistema de apoyo financiero a la internacionalización de la empresa española; la Ley 12/2010, de 30 de junio, por la que se modifica la Ley 19/1988, de 12 de julio, de Auditoría de Cuentas, la Ley 24/1988, de 28 de julio, del Mercado de Valores y el texto refundido de la Ley de Sociedades Anónimas aprobado por el Real Decreto Legis- 
lativo 1564/1989, de 22 de diciembre, para su adaptación a la normativa comunitaria, y la Ley 15/2010, de 5 de julio, de modificación de la Ley 3/2004, de 29 de diciembre, por la que se establecen medidas de lucha contra la morosidad en las operaciones comerciales.

Sobre seguridad social y protección frente al desempleo cabe citar la Ley 32/2010, de 5 de agosto, por la que se establece un sistema específico de protección por cese de actividad de los trabajadores autónomos y la Ley 35/2010, de 17 de septiembre, de medidas urgentes para la reforma del mercado de trabajo.

Esta segunda norma, según su Exposición de Motivos «tiene como objetivo esencial contribuir a la reducción del desempleo e incrementar la productividad de la economía española. A estos efectos, se dirige a corregir la dualidad de nuestro mercado de trabajo promoviendo la estabilidad en el empleo y a incrementar la flexibilidad interna de las empresas, como aspectos más destacables.

De manera más concreta, las medidas incluidas en esta norma se dirigen a lograr tres objetivos fundamentales.

Primero, reducir la dualidad de nuestro mercado laboral, impulsando la creación de empleo estable y de calidad, en línea con los requerimientos de un crecimiento más equilibrado y sostenible.

Segundo, reforzar los instrumentos de flexibilidad interna en el desarrollo de las relaciones laborales y, en particular, las medidas de reducción temporal de jornada, como mecanismo que permita el mantenimiento del empleo durante las situaciones de crisis económica, reduciendo el recurso a las extinciones de contratos y ofreciendo mecanismos alternativos más sanos que la contratación temporal para favorecer la adaptabilidad de las empresas.

Tercero, elevar las oportunidades de las personas desempleadas, con particular atención a los jóvenes, reordenando para ello la política de bonificaciones a la contratación indefinida para hacerla más eficiente, haciendo más atractivos para empresas y trabajadores los contratos formativos y mejorando los mecanismos de intermediación laboral».

En cuanto a la protección de la salud destaca la Ley 42/2010, de 30 de diciembre, por la que se modifica la Ley 28/2005, de 26 de diciembre, de medidas sanitarias frente al tabaquismo y reguladora de la venta, el suministro, el consumo y la publicidad de los productos del tabaco.

Según su Preámbulo, «la La Ley 28/2005, de 26 de diciembre, de medidas sanitarias frente al tabaquismo y reguladora de la venta, el suministro, el consumo y la publicidad de los productos del tabaco, supuso un hito importante en la política de nuestro país en la lucha contra el tabaquismo, tanto en lo que se refiere a la prohibición de fumar en lugares públicos como a las medidas encaminadas a 
potenciar la deshabituación del tabaco y a tratar de erradicar a medio y largo plazo el hábito de fumar.

Transcurridos más de cuatro años de aplicación de la Ley, es patente, como se desprende de diversos estudios realizados al respecto, la necesidad de avanzar en la protección de la salud de los ciudadanos ampliando la prohibición de fumar en espacios públicos cerrados y colectivos, lo que, por otro lado, satisface las demandas de los ciudadanos, como corroboran encuestas oficiales recientemente realizadas.

Dos son los colectivos especialmente beneficiados de esta medida. Por un lado, el de menores, grupo especialmente sensible de población que está expuesto al humo del tabaco en los lugares públicos cerrados. Por otro lado, el de trabajadores del sector de la hostelería que se encuentra claramente desprotegido con respecto al resto de los trabajadores, al estar expuestos al humo de tabaco ajeno.

Por todo ello, y en la línea seguida en materia de prevención y control del tabaquismo por la Unión Europea, con una estrategia concreta de la Comisión Europea, cuyo objetivo es ampliar la prohibición de fumar en espacios cerrados en todos los Estados miembros en 2012, posición que corrobora la ratificación por España, en diciembre de 2004, del Convenio Marco para el Control del Tabaco de la OMS, esta ley, que modifica la Ley 28/2005, se encamina a avanzar en las limitaciones tendentes a aumentar los espacios libres de humo del tabaco.

Para la protección medioambiental se aprobaron la Ley 6/2010, de 24 de marzo, de modificación del texto refundido de la Ley de Evaluación de Impacto Ambiental de proyectos, aprobado por el Real Decreto Legislativo 1/2008, de 11 de enero; la Ley 13/2010, de 5 de julio, por la que se modifica la Ley 1/2005, de 9 de marzo, por la que se regula el régimen del comercio de derechos de emisión de gases de efecto invernadero, para perfeccionar y ampliar el régimen general de comercio de derechos de emisión e incluir la aviación en el mismo y la Ley $41 / 2010$, de 29 de diciembre, de protección del medio marino.

Para la protección de los consumidores se aprobó la Ley 43/2010, de 30 de diciembre, del servicio postal universal, de los derechos de los ususarios y del mercado postal.

Finalmente, debe recordarse que, por vez primera en el actual período constitucional, el Gobierno decretó el estado de alarma en virtud del Real Decreto $1673 / 2010$, de 4 de diciembre ${ }^{11}$, por el que se declara el estado de alarma para la normalización del servicio público esencial del transporte aéreo.

Según declara el propio Decreto, «las circunstancias extraordinarias que concurren por el cierre del espacio aéreo español como consecuencia de la situa-

${ }^{11}$ http://www.boe.es/boe/dias/2010/12/04-2/pdfs/BOE-A-2010-18683.pdf 
ción desencadenada por el abandono de sus obligaciones por parte de los controladores civiles de tránsito aéreo, impiden el ejercicio del derecho fundamental mencionado y determinan la paralización de un servicio público esencial para la sociedad como lo es el servicio de transporte aéreo. Todo ello constituye, sin duda, una calamidad pública de enorme magnitud por el muy elevado número de ciudadanos afectados, la entidad de los derechos conculcados y la gravedad de los perjuicios causados. Para recuperar la normalidad en la prestación del citado servicio público y restablecer los derechos fundamentales de los ciudadanos, hoy menoscabados, y habiendo fracasado todos los intentos para poner fin a la situación de catástrofe pública existente, es indispensable proceder a la declaración del Estado de Alarma en orden a eliminar los obstáculos que impiden su segura y continuada prestación.

De acuerdo con el artículo 3, «todos los controladores de tránsito aéreo al servicio de AENA pasan a tener, durante la vigencia del Estado de Alarma, la consideración de personal militar... y en consecuencia, quedan sometidos a las órdenes directas de las autoridades designadas en el presente real decreto, y a las leyes penales y disciplinarias militares, de conformidad con lo dispuesto en el artículo 8.5 de la Ley Orgánica 13/1985, de 9 de diciembre». 